\title{
Control of charge state of dopants in insulating crystals: Case study of Ti-doped sapphire
}

\author{
L. Yu. Kravchenko ${ }^{1}$ and D. V. Fil $\circledast^{1,2, *}$ \\ ${ }^{1}$ Institute for Single Crystals, National Academy of Sciences of Ukraine, 60 Nauky Avenue, Kharkiv 61072, Ukraine \\ ${ }^{2}$ V. N. Karazin Kharkiv National University, 4 Svobody Square, Kharkiv 61022, Ukraine
}

(Received 1 November 2019; accepted 3 April 2020; published 7 May 2020)

\begin{abstract}
We study mechanisms of control of charge state and concentration of different point defects in doped insulating crystals. The approach is based on the density functional theory calculations. We apply it to the problem of obtaining of Ti-doped sapphire crystals with high figure of merit (FOM). The FOM of a given sample is defined as the ratio of the coefficient of absorption at the pump frequency to the coefficient of absorption at the working frequency of a Ti:sapphire laser. It is one of standard specifications of commercial Ti:sapphire laser crystals. It is believed that the FOM is proportional to the ratio of the concentration of isolated $\mathrm{Ti}^{3+}$ ions to the concentration of $\mathrm{Ti}^{3+}-\mathrm{Ti}^{4+}$ pairs. We find that generally this ratio is in inverse proportion to the concentration of $\mathrm{Ti}^{4+}$ isolated substitutional defects with the coefficient of proportionality that depends on the temperature at which the thermodynamic equilibrium concentration of defects is reached. We argue that in certain cases the inverse proportion between concentrations of $\mathrm{Ti}^{3+}-\mathrm{Ti}^{4+}$ and $\mathrm{Ti}^{4+}$ may be violated. The role of codoping in the control of the charge state of dopants is analyzed. We show that codopants that form positively (negatively) charged defects may decrease (increase) the concentration of positively charged defects formed by the main dopants. To evaluate the effect of codoping it is important to take into account not only isolated defects but defect complexes formed by codopants, as well. In particular, we show that codoping of Ti:sapphire with nitrogen results in an essential increase of the concentration of $\mathrm{Ti}^{4+}$ and in a decrease of the FOM, and, consequently, growth or annealing in the presence of nitrogen or its compounds is unfavorable for producing Ti:sapphire laser crystals. The approach developed can be used for determining appropriate growth and annealing conditions for obtaining doped crystals with the required characteristics.
\end{abstract}

DOI: 10.1103/PhysRevResearch.2.023135

\section{INTRODUCTION}

Doping of insulating crystals with active ions is a widely used method of obtaining functional materials (active laser medium, luminescent materials, scintillators, and many others) with required properties. Usually, in such materials dopant ions should be a certain charge state, occupy certain crystallography positions, and not form (or, instead, form) complexes with other dopant ions or intrinsic defects. The problem of control of the state of the dopant in a host matrix remains very important.

Density functional theory (DFT) is a powerful tool for evaluation of efficiency of different methods of such control. Using the results of DFT calculations and thermochemical data one can analyze finite-temperature properties. In particular, one can calculate equilibrium concentrations of different defects at a given temperature. Due to the condition of overall charge neutrality of defects the concentration of a given charged defect species cannot be calculated independently: in the general case this concentration depends on formation

\footnotetext{
*fil@isc.kharkov.ua

Published by the American Physical Society under the terms of the Creative Commons Attribution 4.0 International license. Further distribution of this work must maintain attribution to the author(s) and the published article's title, journal citation, and DOI.
}

energies of all charged defects. One can imply that equilibrium (or almost equilibrium) concentrations of defects are reached under annealing. Therefore the temperature that enters into equations for equilibrium concentrations of defects can be associated with the temperature of annealing. For as-grown samples it can be replaced with the melting temperature $T_{m}$. The situation becomes more complicated in a situation where concentration of dopants that enter into the crystal under its growth is smaller than their equilibrium concentration at $T=T_{m}$. In this case the concentration of a given species depends on the formation energies of all charged and uncharged defects.

In this paper we consider the problem of control of the charge state of dopants with reference to Ti-doped sapphire crystals. Some elements of our approach were already presented in our previous paper [1], where the results of DFT study of defect complexes of Ti-doped sapphire were reported.

We start with a short introduction where we describe the problem as it is formulated in the materials science community.

Ti:sapphire is a widely used active laser medium. Operation of a Ti: $\mathrm{Al}_{2} \mathrm{O}_{3}$ tunable laser was first reported by Moulton [2] in 1982. An active ion in Ti:sapphire is $\mathrm{Ti}^{3+}$ substituted for the octahedrally coordinated $\mathrm{Al}^{3+}$. This ion has a single $3 d$ electron above a closed shell. Five $d$-electron levels are split by the crystal field into an $e_{g}$ doublet and $t_{2 g}$ triplet. Transitions between the $t_{2 g}$ and $e_{g}$ levels are responsible for the absorption of visible light and near-infrared fluorescence 
$[3,4]$. Titanium substituted for the $\mathrm{Al}$ ion can also be in the $\mathrm{Ti}^{4+}$ state. A charge-transfer transition between $\mathrm{O}^{2-}$ and $\mathrm{Ti}^{4+}$ causes ultraviolet (UV) absorption in Ti:sapphire [5]. Measurement of UV spectral characteristics gives the information on the concentration of $\mathrm{Ti}^{4+}$ ions in Ti:sapphire samples [5,6].

Ti:sapphire exhibits weak near-infrared (NIR) absorption $[3,4,7-10]$ that results in losses at the wavelength of the laser emission. To qualify the performance of Ti:sapphire as a laser crystal the ratio of the absorption $\alpha_{m}$ at the pump wavelength $\left(\lambda_{m} \approx 500 \mathrm{~nm}\right)$ to the absorption $\alpha_{r}$ at the laser emission wavelength $\left(\lambda_{r} \approx 800 \mathrm{~nm}\right)$ is used. This ratio is known as a figure-of-merit (FOM) characterization of commercial materials. To calculate the FOM one should specify exact values of $\lambda_{m}$ and $\lambda_{r}$. One of the accepted choices is $\lambda_{m}=514 \mathrm{~nm}$ and $\lambda_{r}=820 \mathrm{~nm}$ [11]. Slightly different $\lambda_{m}$ and $\lambda_{r}$ are also accepted [9].

NIR absorption is associated with $\mathrm{Ti}^{3+}-\mathrm{Ti}^{4+}$ pairs. A correlation between NIR absorption and the concentration of $\mathrm{Ti}^{3+}-\mathrm{Ti}^{4+}$ pairs was demonstrated in Ref. [9] where the dependence of $\alpha_{r}$ on $\alpha_{m}$ was measured. A partially oxidized sample studied in Ref. [9] was clear near the surface and pink inside that visualized a variation of the concentration of $\mathrm{Ti}^{3+}$ across the sample. The total concentration of $\mathrm{Ti} c_{\mathrm{Ti}}$ was a constant. The obtained dependence of $\alpha_{r}$ on $\alpha_{m}$ is of a bell-like shape. This dependence is described by the formula $\alpha_{r} \propto$ $\alpha_{m}\left(\alpha_{0}-\alpha_{m}\right)$, where $\alpha_{0}$ is some constant. It is believed that the concentration of $\mathrm{Ti}^{3+}-\mathrm{Ti}^{4+}$ pairs $\left(c_{\mathrm{Ti}^{3+}-\mathrm{Ti}^{4+}}\right)$ is proportional to the product of concentrations of isolated $\mathrm{Ti}^{3+}$ and $\mathrm{Ti}^{4+}$ ions. The first one is proportional to $\alpha_{m}$, and the second, to $c_{\mathrm{Ti}^{-}}-c_{\mathrm{Ti}^{3+}} \propto \alpha_{0}-\alpha_{m}$. Therefore the observation [9] correlates with the expectation that the adsorption coefficient $\alpha_{r}$ depends linearly on $c_{\mathrm{Ti}^{3+}-\mathrm{Ti}^{4+}}$. The pair mechanism of NIR absorption is supported by calculations of energy levels of the $\mathrm{Ti}^{3+} \mathrm{Ti}^{4+} \mathrm{O}_{9}^{2-}$ cluster [12]. The energy difference [12] between the ground state and the first excited level of such a cluster corresponds to the wavelength $\lambda=813 \mathrm{~nm}$ that is in excellent agreement with the experimental value of $\lambda$ at which the maximum of NIR absorption is observed.

The problem of NIR absorption was revisited recently in [13] where the absorption data in the range of wavelengths from $190 \mathrm{~nm}$ to $2000 \mathrm{~nm}$ were analyzed with reference to many Ti:sapphire samples of different origin. A sample with a large fraction of $\mathrm{Ti}^{4+}$ (that was confirmed by a very weak absorption by this sample at $\lambda=490 \mathrm{~nm}$ ) was used as a reference. The $\mathrm{Ti}^{4+}$ scaling factor was defined as the absorption at $\lambda=225 \mathrm{~nm}$ by a given sample related to the absorption by the reference sample. It was implied that this factor is proportional to the concentration of $\mathrm{Ti}^{4+}$. If NIR is caused by $\mathrm{Ti}^{3+}-\mathrm{Ti}^{4+}$ pairs, the FOM will be in inverse proportion to the $\mathrm{Ti}^{4+}$ scaling factor. Nevertheless, some samples demonstrated strong deviation from this law. Based on this observation the authors of Ref. [13] arrived at the conclusion that the $\mathrm{Ti}^{3+}-\mathrm{Ti}^{4+}$ pair model of NIR absorption needs a revision.

Defect energetics in Ti:sapphire were investigated within the DFT approach in Refs. [14,15]. It was shown that in the oxidized conditions $\mathrm{Ti}^{4+}$ ions substituted for $\mathrm{Al}^{3+}$ ions together with charge-compensating vacancies of $\mathrm{Al}\left(V_{\mathrm{Al}}^{3-}\right)$ are the most stable defects. In the reduced conditions the formation energy of substitutional $\mathrm{Ti}^{3+}$ ions is of the smallest value. In the intermediate range of the oxygen potential the substitutional $\mathrm{Ti}^{3+}$ and $\mathrm{Ti}^{4+}$ defects exhibit similar formation energies, indicating that they can coexist. It was established that $\mathrm{Ti}^{3+}$ ions demonstrate a tendency to form pairs and larger clusters. The binding energy of the $\mathrm{Ti}^{3+}-\mathrm{Ti}^{3+}$ pair strongly depends on the distance between $\mathrm{Ti}^{3+}$ ions. For the first nearest neighbors this energy is about $1.2 \mathrm{eV}$, but for the third nearest neighbors it is less than $0.2 \mathrm{eV}$. The binding energy of $\mathrm{Ti}^{3+}$ triples and quadruples is about $2 \mathrm{eV}$ and $3 \mathrm{eV}$, correspondingly. In addition, positively charged $\mathrm{Ti}^{4+}$ ions bind in pairs with negatively charged $\mathrm{Al}$ vacancies $V_{\mathrm{Al}}^{3-}$ with almost the same binding energy as one of $\mathrm{Ti}^{3+}-\mathrm{Ti}^{3+}$ pairs. Energetics of defect complexes in Ti-doped sapphire was studied in detail in Ref. [1]. The formation energies and the binding energy of pairs, triples, and quadruples formed by $\mathrm{Ti}^{3+}, \mathrm{Ti}^{4+}$, and $V_{\mathrm{Al}}^{3-}$ were calculated. It was shown that equilibrium concentrations of complex defects can be on the same order of or even larger than the concentration of isolated $\mathrm{Ti}^{3+}$ or $\mathrm{Ti}^{4+}$ defects. It was found that complex defects in Ti:sapphire influence significantly the balance between charged defects.

In this paper we present a thorough investigation of the problem of control of the charge state of titanium in Ti:sapphire. Our investigation complements the study $[14,15]$ and our recent study [1].

The method for the calculation of defect formation energies and of dopant concentration presented in Secs. III-V is the central result of this paper. It can be applied to dopant and defect complexes in different technologically relevant materials. In Secs. V and VI we answer a number of questions that arose in Ref. [13] and clarify the role of several factors that may increase the FOM such as an appropriate choice of the temperature of annealing, adding of certain compounds into the atmosphere, or into the melt under the growth or annealing, codoping with nonisovalent atoms. This analysis is another principal result of the paper. The approach developed is quite general and can be used for determining appropriate growth and annealing conditions to control the charge state of dopants in various insulating crystals not restricted to Ti:sapphire.

\section{EQUILIBRIUM CONCENTRATION OF DEFECTS AND UNIVERSAL RELATION BETWEEN CONCENTRATIONS OF SIMPLE AND COMPLEX DEFECTS}

In this section we derive the general relation between equilibrium concentrations of isolated and complex defects and show that this relation also takes place if the total number of dopant atoms is fixed.

Equilibrium concentrations of defects can be obtained from the condition of the minimum of the free energy. The free energy depends on the defect formation energies $E_{i}$ and the configurational entropy $\ln W$, where $W$ is the number of ways to place defects in the crystal:

$$
F=F_{0}+\sum_{i} E_{i} n_{i}-k_{\mathrm{B}} T \ln W .
$$

In Eq. (1) $F_{0}$ is the free energy of the perfect crystal, the sum is taken over all possible defect species, $n_{i}$ is the number of defects of the $i$ th species, $T$ is the temperature, and $k_{\mathrm{B}}$ is the Boltzmann constant. We imply that the total number of 
defects $n_{\text {tot }}=n_{i_{1}}+n_{i_{2}}+\cdots$ is much smaller than the number of lattice sites and approximate $W$ by the equation

$$
W \approx \prod_{i} \frac{N_{i} !}{\left(N_{i}-n_{i}\right) ! n_{i} !},
$$

where $N_{i}$ is the number of different positions and orientations for the $i$ th defect species.

We take into account that overall electric charge of all charged defects is zero. This results in the constraint

$$
\sum_{i} q_{i} n_{i}=0
$$

where $q_{i}$ is the electrical charge of the $i$ th defect (below we use elementary charge units for $q_{i}$ ). If the total number of dopant in the crystal is fixed we have the additional constraint

$$
\sum_{i} k_{\mathrm{Ti}, i} n_{i}=n_{\mathrm{Ti}}
$$

Here we specify the case of Ti dopants. In Eq. (4) $k_{\mathrm{Ti}, i}$ is the number of $\mathrm{Ti}$ atoms per an $i$ th defect and $n_{\mathrm{Ti}}$ is the total number of Ti ions in the crystal. The constraint (4) should be taken into account if an actual concentration of dopant differs from its equilibrium concentration at $T=T_{m}$ (for as-grown samples) or at the temperature of annealing.

The free energy minimum with the additional constraints can be found by the method of Lagrange multipliers. The constraints (3) and (4) can be taken into account by two additional terms with two Lagrange multipliers $\lambda_{q}$ and $\lambda_{\mathrm{Ti}}$. The extremum condition yields

$$
\tilde{n}_{i}=\frac{n_{i}}{N_{i}}=\exp \left(-\frac{E_{i}-\lambda_{q} q_{i}-\lambda_{\mathrm{Ti}} k_{\mathrm{Ti}, i}}{k_{\mathrm{B}} T}\right) .
$$

Substituting Eq. (5) into Eqs. (3) and (4) we obtain two equations for $\lambda_{q}$ and $\lambda_{\mathrm{Ti}}$.

One can find the general relation between the concentrations of isolated and complex defects using Eq. (5). Let us consider a complex defect $i_{c}$ composed of $r_{1}+r_{2}+\cdots+r_{s}$ simple defects:

$$
i_{c}=\underbrace{i_{1} \ldots i_{1}}_{r_{1} \text { times }} \underbrace{i_{2} \ldots i_{2}}_{r_{2} \text { times }} \ldots \underbrace{i_{s} \ldots i_{s}}_{r_{s} \text { times }} .
$$

For such a defect Eq. (5) can be rewritten as

$$
\begin{aligned}
\tilde{n}_{i_{c}}= & \exp \left(\frac{E_{i_{c}}^{(b)}}{k_{\mathrm{B}} T}\right) \prod_{j=1}^{s}\left[\exp \left(-\frac{E_{i_{j}}-\lambda_{q} q_{i_{j}}-\lambda_{\mathrm{Ti}} k_{\mathrm{Ti}, i_{j}}}{k_{\mathrm{B}} T}\right)\right]^{r_{j}} \\
& \times \exp \frac{\lambda_{q}\left(q_{i_{c}}-\sum_{j=1}^{s} r_{j} q_{i_{j}}\right)}{k_{\mathrm{B}} T} \\
& \times \exp \frac{\lambda_{\mathrm{Ti}}\left(k_{\mathrm{Ti}, i_{c}}-\sum_{j=1}^{s} r_{j} k_{\mathrm{Ti}, i_{j}}\right)}{k_{\mathrm{B}} T}
\end{aligned}
$$

where

$$
E_{i_{c}}^{(b)}=\sum_{j=1}^{s} r_{j} E_{i_{j}}-E_{i_{c}}
$$

is the binding energy of the complex defect $i_{c}$. Charge and particle number conservation requires $q_{i_{c}}=\sum_{j=1}^{s} r_{j} q_{i_{j}}$ and
$k_{\mathrm{Ti}, i_{c}}=\sum_{j=1}^{s} r_{j} k_{\mathrm{Ti}, i_{j}}$. Thus Eq. (7) reduces to

$$
\tilde{n}_{i_{c}}=\exp \left(\frac{E_{i_{c}}^{(b)}}{k_{\mathrm{B}} T}\right)\left(\tilde{n}_{i_{1}}\right)^{r_{1}}\left(\tilde{n}_{i_{2}}\right)^{r_{2}} \ldots\left(\tilde{n}_{i_{s}}\right)^{r_{s}} .
$$

Considering the problem with only one constraint (3) we put $\lambda_{\mathrm{Ti}}=0$ from the beginning and again arrive at the relation (9).

In the DFT approach the defect formation energy is given by the equation $[16,17]$

$$
E_{i}=E_{\mathrm{def}, i}-E_{\mathrm{perf}}-\sum_{X} \mu_{X} p_{X, i}+\mu_{e} q_{i}+E_{i}^{(c)},
$$

where $E_{\operatorname{def}, i}$ is the energy of the supercell with a given defect, $E_{\text {perf }}$ is the energy of the perfect supercell, $p_{X, i}$ is the number of atoms of type $X$ (host or impurity atoms) that have been added to $\left(p_{X, i}>0\right)$ or removed from $\left(p_{X, i}<0\right)$ the supercell to form the defect of the $i$ th species, $\mu_{X}$ is the chemical potential of the atom of the type $X, \mu_{e}$ is the electron chemical potential, and $E_{i}^{(c)}$ is the correction that excludes electrostatic interaction caused by periodic coping of charged defects in the supercell calculations.

Substituting Eq. (10) into Eq. (5) and redefining the Lagrange multiplier $\tilde{\lambda}_{q}=\lambda_{q}-\mu_{e}$ one can exclude the electron chemical potential from the problem. This means that equilibrium concentrations of defects can be expressed through the quantities independently of $\mu_{e}$. If the total number of $\mathrm{Ti}$ atoms is fixed, the chemical potential of Ti can be excluded as well. In the latter case equilibrium concentrations of defects do not depend on $\mu_{\mathrm{Ti}}$.

Applying Eq. (9) to Ti:sapphire we find that the ratio of the concentration of isolated $\mathrm{Ti}^{3+}$ ions to the concentration of $\mathrm{Ti}^{3+}-\mathrm{Ti}^{4+}$ pairs is in inverse proportion to the concentration of isolated $\mathrm{Ti}^{4+}$ ions:

$$
\frac{c_{3}}{c_{3-4}}=\frac{e^{-\frac{E_{3-4}^{(b)}}{k_{\mathrm{B}} T}}}{2 \tilde{n}_{4}} .
$$

Here and below we use the notations $3 \equiv \mathrm{Ti}^{3+} \equiv \mathrm{Ti}_{\mathrm{Al}}^{0}, 4 \equiv$ $\mathrm{Ti}^{4+} \equiv \mathrm{Ti}_{\mathrm{Al}}^{+}$, and $3-4 \equiv \mathrm{Ti}^{3+}-\mathrm{Ti}^{4+}$. The factor of 2 in the denominator of Eq. (11) is the number of different positions and orientations of $\mathrm{Ti}^{3+}-\mathrm{Ti}^{4+}$ pairs per one $\mathrm{Al}$ site. The coefficient of proportionality depends on the temperature at which the equilibrium concentration of defects is reached. For defects with positive binding energy (DFT calculations show that $E_{3-4}^{(b)}>0$ ) the coefficient of proportionality decreases under lowering in this temperature. The relation (11) is fulfilled for any total concentration of $\mathrm{Ti}$ (equilibrium at given temperature or fixed to a certain level). At the same time the relation (11) may be violated under additional constraints on the concentrations of defects (see Sec. VI).

\section{CALCULATION OF DEFECT FORMATION ENERGIES}

To calculate defect formation energies we use the Kohn-Sham density functional method in the generalized gradient approximation with the Perdew-Burke-Ernzerhof parametrization for the exchange-correlation functional and double-zeta basis with polarization orbitals as implemented in the open source SIESTA code [18]. The pseudopotentials were generated with the improved Troullier-Martins scheme. 
The Al- $3 s^{2} 3 p^{1}, \mathrm{O}-2 s^{2} 2 p^{4}$, and Ti- $4 s^{1} 3 d^{3}$ electronic states are considered as valence ones. We do not include $3 d$ semicore states into the valence ones due to the following reason. The heats of formation of crystal phases used as references for building the Al-Ti-O phase diagram $\left(\mathrm{TiO}_{2}, \mathrm{Ti}_{3} \mathrm{O}_{5}, \mathrm{Ti}_{2} \mathrm{O}_{3}\right)$ calculated with the use of the 4-electron state of $\mathrm{Ti}$ are in better coincidence with experimental quantities than the ones of the 10-electron state of Ti. In addition, calculations with 10 valence electrons per atom are slower than with 4 . Actually there is no unambiguous answer as to where semicore states should be included [19]. To study codoping with carbon, nitrogen, and fluorine we set C- $2 s^{2} 2 p^{2}, \mathrm{~N}-2 s^{2} 2 p^{3}$, and F- $2 s^{2} 2 p^{5}$ valence electronic states.

Lattice parameters and atomic positions are optimized until the residual stress components converge to less than $0.1 \mathrm{GPa}$ and the residual forces are less than $0.01 \mathrm{eV} / \AA$. The plane-wave cutoff energy of $250 \mathrm{Ry}$ is used to calculate the total energy of the system. A 120-atom supercell of $\alpha-\mathrm{Al}_{2} \mathrm{O}_{3}$ is built of 4 optimized unit cells. One simple or complex defect is placed in the supercell. The optimization of atomic positions in the supercell with a defect is fulfilled again. Numerical integrations over the supercell Brillouin zone are performed at the $\Gamma$ point. To check convergency of the $\Gamma$-point integration we calculate several formation energies integrating over $3 \times 3 \times 3$ and $5 \times 5 \times 5$ grids of $k$ points. Integration over a $3 \times 3 \times 3$ grid yields $\mathrm{Ti}^{3+}, \mathrm{Ti}^{4+}$, and $V_{\mathrm{Al}}^{3-}$ formation energies higher than ones for the $\Gamma$-point integration by $0.02 \mathrm{eV}, 0.027 \mathrm{eV}$, and $0.018 \mathrm{eV}$, correspondingly. The difference of energies given by integration over $3 \times 3 \times 3$ and $5 \times 5 \times 5$ grids of $k$ points is less than $10^{-3} \mathrm{eV}$. Based on this result we conclude that restriction with integration over the $\Gamma$ point (which considerably speeds up the calculations) mainly results in an unessential overestimate (about 10\%) of the total equilibrium concentration of Ti. The error in relative concentrations of different defects is less than $3 \%$.

Chemical potentials of atoms that enter into Eq. (10) are calculated from chemical potentials of materials related to the Al-Ti-O system. The chemical potential of a given material is the sum of the zero-temperature DFT energy and a temperature correction part:

$$
\mu(X)=\mu_{0}(X)+\Delta \mu_{T}(X),
$$

where $\mu_{0}(X)$ is the DFT energy of a crystal (per formula unit), or of an isolated molecule if the material is a gas at the standard conditions. The temperature correction is determined by the equation [20,21]

$$
\Delta \mu_{T}(X)=H_{X}(T, p)-H_{X}(0, p)-T S_{X}(T, p),
$$

where $H_{X}(T, p)$ and $S_{X}(T, p)$ are the enthalpy and entropy at the temperature $T$ and pressure $p$. We put $p=0.1 \mathrm{MPa}$ (standard conditions) and take the values of $H_{X}(T, p)$ and $S_{X}(T, p)$ from the thermochemical tables [22].

The heat of formation $H_{f}$ for a compound with the general formula $X_{u} Y_{v}$, where $X, Y=\mathrm{Al}, \mathrm{Ti}, \mathrm{C}$, is calculated as

$$
H_{f}\left(X_{u} Y_{v}\right)=\frac{\mu\left(X_{u} Y_{v}\right)-u \mu(X)-v \mu(Y)}{u+v}
$$

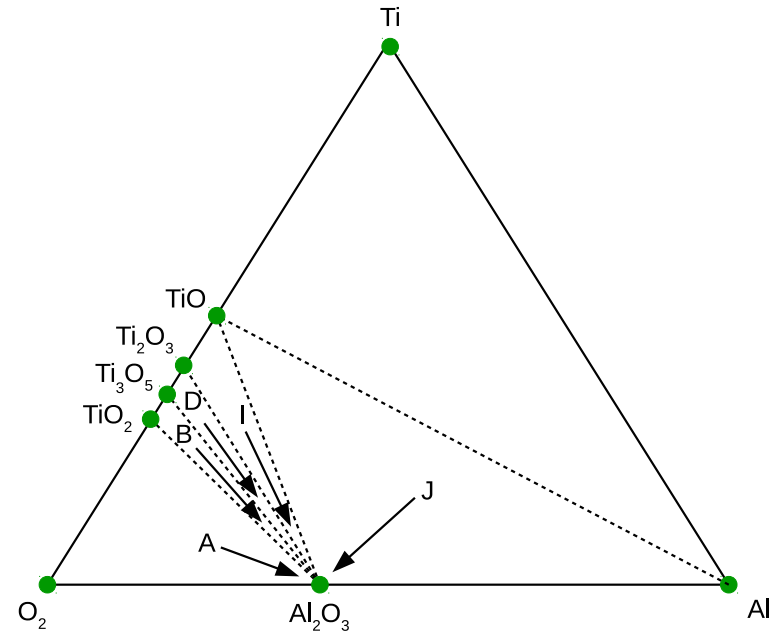

FIG. 1. Phase diagram of the Al-Ti-O system at $T=T_{m}$. The points $\mathrm{A}, \mathrm{B}, \mathrm{D}, \mathrm{I}$, and $\mathrm{J}$ denoted by arrows correspond to the vertices of the three-phase region around $\mathrm{Al}_{2} \mathrm{O}_{3}$.

or, if $Y=\mathrm{O}, \mathrm{N}, \mathrm{F}$, as

$$
H_{f}\left(X_{u} Y_{v}\right)=\frac{\mu\left(X_{u} Y_{v}\right)-u \mu(X)-\frac{v}{2} \mu\left(Y_{2}\right)}{u+v} .
$$

Equations (14) and (15) give heats of formation per one atom. Chemical potentials in Eqs. (14) and (15) take into account the temperature correction Eq. (13). Using calculated heats of formation (14) and (15), we build the Al-Ti-O phase diagram and define points in which $\alpha-\mathrm{Al}_{2} \mathrm{O}_{3}$ is in equilibrium with two other phases. The obtained phase diagram at $T=$ $T_{m}=2327 \mathrm{~K}$ (the melting temperature of $\alpha-\mathrm{Al}_{2} \mathrm{O}_{3}$ ) is shown in Fig. 1. The same procedure is done for four-component systems Al-Ti-O- $X$, where $X=\mathrm{C}, \mathrm{N}, \mathrm{F}$. The reference points in the phase diagrams, where two (three) phases are in equilibrium with $\mathrm{Al}_{2} \mathrm{O}_{3}$, are listed in Table $\mathrm{I}$.

Chemical potentials of atoms are calculated for all reference points using the equations that relate these potentials with the potentials Eq. (12). For instance, for the point A of the ternary system we have

$$
\begin{gathered}
2 \mu_{\mathrm{Al}}+3 \mu_{\mathrm{O}}=\mu\left(\mathrm{Al}_{2} \mathrm{O}_{3}\right), \\
\mu_{\mathrm{Ti}}+2 \mu_{\mathrm{O}}=\mu\left(\mathrm{TiO}_{2}\right), \\
2 \mu_{\mathrm{O}}=\mu\left(\mathrm{O}_{2}\right) .
\end{gathered}
$$

The expression for the defect formation energies (10) contains the difference of the energies of a defect and of the perfect supercell $E_{\mathrm{d}-\mathrm{p}, i}=E_{\mathrm{def}, i}-E_{\mathrm{perf}}$. Within the DFT method we calculate this difference at $T=0$. At finite $T$ one should take into account a temperature correction $\Delta E_{\mathrm{d}-\mathrm{p}, i}(T)$ to this difference. The origin of $\Delta E_{\mathrm{d}-\mathrm{p}, i}(T)$ is differences of finite temperature enthalpy and entropy of a defect and a perfect supercell. We evaluate $\Delta E_{\mathrm{d}-\mathrm{p}, i}(T)$ from the temperature corrections Eq. (13) for relevant materials in the crystal state.

The difference $\Delta E_{\mathrm{d}-\mathrm{p}, \mathrm{Ti}_{\mathrm{Al}}}(T)$ is evaluated from $\Delta \mu_{T}$ for pure $\mathrm{Al}_{2} \mathrm{O}_{3}$ and $\mathrm{Ti}_{2} \mathrm{O}_{3}$ :

$$
\Delta E_{\mathrm{d}-\mathrm{p}, \mathrm{Ti}_{\mathrm{Al}}}(T)=\frac{1}{2}\left[\Delta \mu_{T}\left(\mathrm{Ti}_{2} \mathrm{O}_{3}\right)-\Delta \mu_{T}\left(\mathrm{Al}_{2} \mathrm{O}_{3}\right)\right] .
$$


TABLE I. Phases in equilibrium with $\mathrm{Al}_{2} \mathrm{O}_{3}$ and the oxygen chemical potential in reference points of the ternary and four-component phase diagrams at $T=T_{m}$. The potential $\mu_{\mathrm{O}}$ is counted from the energy of an isolated oxygen atom.

\begin{tabular}{|c|c|c|c|c|c|}
\hline Point & Al-Ti-O & Al-Ti-O-C & Al-Ti-O-N & Al-Ti-O-F & $\mu_{\mathrm{O}}(\mathrm{eV})$ \\
\hline A & $\mathrm{O}_{2}, \mathrm{TiO}_{2}$ & $\mathrm{O}_{2}, \mathrm{TiO}_{2}, \mathrm{CO}_{2}$ & $\mathrm{O}_{2}, \mathrm{TiO}_{2}, \mathrm{~N}_{2}$ & $\mathrm{O}_{2}, \mathrm{TiO}_{2}, \mathrm{AlF}_{3}$ & -7.29 \\
\hline $\begin{array}{l}\mathrm{B} \\
\mathrm{C}\end{array}$ & $\mathrm{TiO}_{2}, \mathrm{Ti}_{3} \mathrm{O}_{5}$ & $\begin{array}{c}\mathrm{TiO}_{2}, \mathrm{Ti}_{3} \mathrm{O}_{5}, \mathrm{CO}_{2} \\
\mathrm{Ti}_{3} \mathrm{O}_{5}, \mathrm{CO}_{2}, \mathrm{CO}\end{array}$ & $\mathrm{TiO}_{2}, \mathrm{Ti}_{3} \mathrm{O}_{5}, \mathrm{~N}_{2}$ & $\mathrm{TiO}_{2}, \mathrm{Ti}_{3} \mathrm{O}_{5}, \mathrm{AlF}_{3}$ & $\begin{array}{l}-8.37 \\
-9.24\end{array}$ \\
\hline $\begin{array}{l}\mathrm{D} \\
\mathrm{E}\end{array}$ & $\mathrm{Ti}_{3} \mathrm{O}_{5}, \mathrm{Ti}_{2} \mathrm{O}_{3}$ & $\mathrm{Ti}_{3} \mathrm{O}_{5}, \mathrm{Ti}_{2} \mathrm{O}_{3}, \mathrm{CO}$ & $\begin{array}{c}\mathrm{Ti}_{3} \mathrm{O}_{5}, \mathrm{Ti}_{2} \mathrm{O}_{3}, \mathrm{~N}_{2} \\
\mathrm{Ti}_{2} \mathrm{O}_{3}, \mathrm{~N}_{2}, \mathrm{TiN}\end{array}$ & $\mathrm{Ti}_{3} \mathrm{O}_{5}, \mathrm{Ti}_{2} \mathrm{O}_{3}, \mathrm{AlF}_{3}$ & $\begin{array}{l}-9.75 \\
-9.88\end{array}$ \\
\hline $\mathrm{F}$ & & $\mathrm{Ti}_{2} \mathrm{O}_{3}, \mathrm{CO}, \mathrm{TiC}$ & & & -10.06 \\
\hline G & & $\mathrm{CO}, \mathrm{TiC}, \mathrm{C}$ & & & -10.24 \\
\hline $\mathrm{H}$ & & & $\mathrm{N}_{2}$, TiN, AlN & & -10.30 \\
\hline I & $\mathrm{Ti}_{2} \mathrm{O}_{3}, \mathrm{TiO}$ & $\mathrm{Ti}_{2} \mathrm{O}_{3}, \mathrm{TiO}, \mathrm{TiC}$ & $\mathrm{Ti}_{2} \mathrm{O}_{3}, \mathrm{TiO}, \mathrm{TiN}$ & $\mathrm{Ti}_{2} \mathrm{O}_{3}, \mathrm{TiO}, \mathrm{AlF}_{3}$ & -10.36 \\
\hline $\mathrm{J}$ & $\mathrm{TiO}, \mathrm{Al}$ & $\mathrm{TiO}, \mathrm{Al}, \mathrm{TiC}$ & TiO, Al, TiN & $\mathrm{TiO}, \mathrm{Al}, \mathrm{AlF}_{3}$ & -10.45 \\
\hline $\mathrm{K}$ & & & Al, TiN, AlN & & -10.45 \\
\hline $\mathrm{L}$ & & $\mathrm{Al}, \mathrm{TiC}, \mathrm{C}$ & & & -10.45 \\
\hline
\end{tabular}

To evaluate the temperature correction for the supercell with a vacancy we imply that

$$
3 \Delta E_{\mathrm{d}-\mathrm{p}, V_{\mathrm{O}}}(T)+2 \Delta E_{\mathrm{d}-\mathrm{p}, V_{\mathrm{Al}}}(T)=-\Delta \mu_{T}\left(\mathrm{Al}_{2} \mathrm{O}_{3}\right) .
$$

Equation (20) can be justified as follows. If one removes an integer number of formula units from the supercell and rearranges atoms one can obtain another perfect supercell. The formation energy of such a "defect" is equal to zero and the temperature correction to $E_{i}$ is equal to zero as well. The temperature correction to $E_{i}$ contains the corrections to $\mu_{X}$ and to $E_{\text {def }, i}-E_{\text {perf }}$ and they should cancel each other. Equation (20) provides the fulfillment of this condition. Assuming that $\Delta E_{\mathrm{d}-\mathrm{p}, V_{X}}(T)$ (with $X=\mathrm{Al}, \mathrm{Ti}, \mathrm{O}$ ), are the same for $\mathrm{Al}_{2} \mathrm{O}_{3}, \mathrm{Ti}_{2} \mathrm{O}_{3}$ and $\mathrm{TiO}_{2}$, we calculate $\Delta E_{\mathrm{d}-\mathrm{p}, V_{\mathrm{Al}}}(T)$ and $\Delta E_{\mathrm{d}-\mathrm{p}, V_{\mathrm{o}}}(T)$ using equations

$$
\begin{gathered}
3 \Delta E_{\mathrm{d}-\mathrm{p}, V_{\mathrm{O}}}(T)+2 \Delta E_{\mathrm{d}-\mathrm{p}, V_{\mathrm{Ti}}}(T)=-\Delta \mu_{T}\left(\mathrm{Ti}_{2} \mathrm{O}_{3}\right), \\
2 \Delta E_{\mathrm{d}-\mathrm{p}, V_{\mathrm{O}}}(T)+\Delta E_{\mathrm{d}-\mathrm{p}, V_{\mathrm{Ti}}}(T)=-\Delta \mu_{T}\left(\mathrm{TiO}_{2}\right),
\end{gathered}
$$

and Eq. (20).

Temperature corrections to the energies of substitutional $\mathrm{N}$, $\mathrm{C}$, and $\mathrm{F}$ defects are evaluated from $\Delta \mu_{T}(\mathrm{AlN}), \Delta \mu_{T}\left(\mathrm{Al}_{4} \mathrm{C}_{3}\right)$, and $\Delta \mu_{T}\left(\mathrm{AlF}_{3}\right)$, correspondingly. For instance, to evaluate $\Delta E_{\mathrm{d}-\mathrm{p}, \mathrm{N}_{\mathrm{O}}}(T)$ we use the relation

$$
\Delta E_{\mathrm{d}-\mathrm{p}, \mathrm{N}_{\mathrm{O}}}(T)=\Delta \mu_{T}(\mathrm{AlN})+\Delta E_{\mathrm{d}-\mathrm{p}, V_{\mathrm{Al}}}(T)+\Delta E_{\mathrm{d}-\mathrm{p}, V_{\mathrm{o}}}(T) \text {. }
$$

Equation (23) is based on the fact that the $\mathrm{N}_{\mathrm{O}}$ defect can be created by removing one $\mathrm{Al}$ and one $\mathrm{O}$ atom from the $\mathrm{Al}_{2} \mathrm{O}_{3}$ crystal and adding one formula unit of AlN. Similar arguments were used to evaluate $\Delta E_{\mathrm{d}-\mathrm{p}, \mathrm{C}_{\mathrm{O}}}(T), \Delta E_{\mathrm{d}-\mathrm{p}, \mathrm{C}_{\mathrm{Al}}}(T)$, and $E_{\mathrm{d}-\mathrm{p}, \mathrm{F}_{\mathrm{o}}}(T)$. The temperature correction $\Delta E_{\mathrm{d}-\mathrm{p}, i_{c}}(T)$ for a complex defect is taken as the sum of $\Delta E_{\mathrm{d}-\mathrm{p}, i}(T)$ for simple defects which form this complex defect.

The correction $E_{i}^{(c)}$ in the expression for the defect formation energy (10) is evaluated by a method similar to the one proposed in Refs. [23,24]. DFT supercell calculations give the formation energies $E_{i}^{(0)}$ with spurious electrostatic interaction between periodically arranged charged defects. Calculations of the charge distribution show that the defect charge is strongly localized. Therefore, the main contribution to the electrostatic energy comes from the monopole-monopole interaction, while the contribution of the monopole-dipole and dipole-dipole interaction $[25,26]$ is much smaller. This allows us to equate $E_{i}^{(c)}$ with the Madelung energy taken with a negative sign. We imply that the Madelung energy for a supercell composed of $n \times m \times k$ unit cells can be presented in the form

$$
E_{M}(n, m, k)=\frac{q_{i, \mathrm{eff}}^{2}}{2 \epsilon_{\mathrm{eff}}} \tilde{E}_{M}(n, m, k)
$$

where $q_{\text {eff }}$ is the effective charge of the defect, $\varepsilon_{\text {eff }}$ is the effective dielectric constant, and $\tilde{E}_{M}(n, m, k)$ is the electrostatic energy of a periodic structure of $q=1$ point charges in the medium with $\varepsilon=1$ and with a charge-compensating background. For a cubic lattice $\tilde{E}_{M}(n, n, n)=-2.837 / n a$, where $a$ is the lattice parameter. In the general case $\tilde{E}_{M}(n, m, k)$ depends on the size and the form of the supercell. For elongated supercells it can be positive.

For each defect species we calculate the supercell defect formation energy $E_{i}^{(0)}$ for five different supercells: $(2,2,1)$, $(2,3,1),(3,3,1),(2,2,2)$, and $(2,2,3)$. Each supercell is built from hexagonal unit cells with lattice parameters $a=b=$ $4.86 \AA$ and $c=13.19 \AA$ obtained for pure $\mathrm{Al}_{2} \mathrm{O}_{3}$ by optimization of lattice vectors. Then, we calculate the Madelung energy $\tilde{E}_{M}$ by the Ewalds method for the same supercells, define the dimensionless quantity $v_{M}(n, m, k)=a \tilde{E}_{M}(n, m, k)$, and fit the energy $E_{i}^{(0)}$ by a linear function:

$$
E_{i}^{(0)}\left(v_{M}\right)=E_{i}+\frac{q_{i, \mathrm{eff}}^{2}}{2 \epsilon_{\mathrm{eff}} a} v_{M}=c_{0, i}+c_{1, i} v_{M} .
$$

As two examples we present the result of fitting for $\mathrm{Ti}^{4+}$ and $V_{\mathrm{Al}}^{3-}$ in Fig 2. Taking into account that for infinitely large supercell $v_{M}(n, m, k)=0$, we evaluate the corrected formation energy as $E_{i}=c_{0, i}$ and the correction $E_{i}^{(c)}$, as $E_{i}^{(c)}(n, m, k)=c_{0, i}-E_{i}^{(0)}(n, m, k)$. Calculated electrostatic corrections $E_{i}^{(c)}(2,2,1)$ for the considered charged defects are given in Table II. Note that if we set $\varepsilon_{\text {eff }}=10$ we obtain the effective charges $\left|q_{\mathrm{Ti}^{4+}, \text { eff }} / e\right|=0.76$ and $\left|q_{V_{\mathrm{Al}}^{3-} \text {,eff }} / e\right|=2.52$, which looks reasonable. 

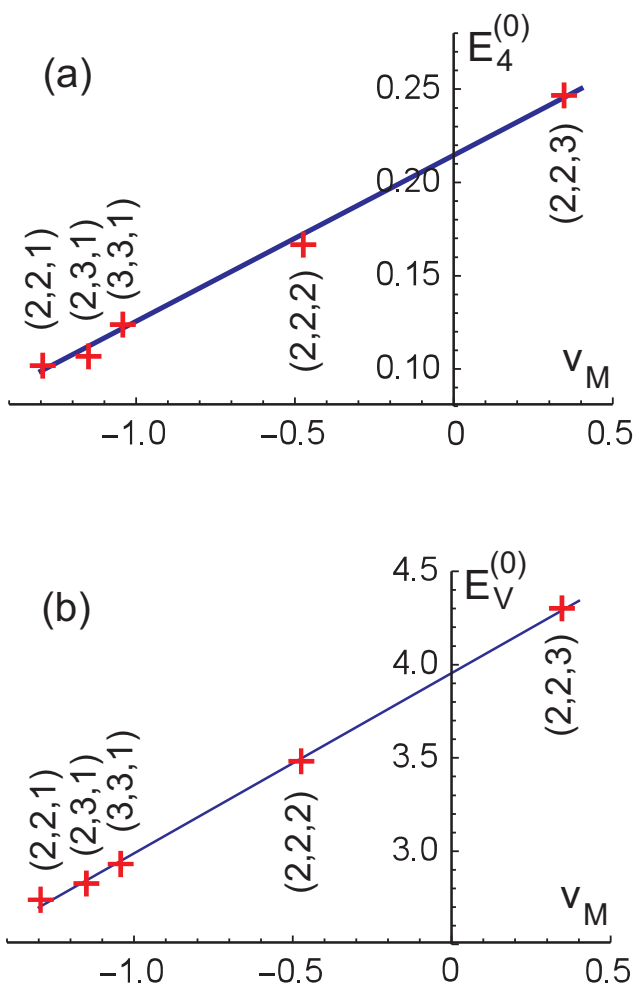

FIG. 2. Calculated defect formation energies $E_{i}^{(0)}$ (in $\mathrm{eV}$ ) for $\mathrm{Ti}^{4+}$ (a) and $V_{\mathrm{Al}}^{3-}$ (b) for several supercells versus $v_{M}$ and linear fit (25). For concreteness, we set $\mu_{e}$ equal to the valence band maximum.

\section{EQUILIBRIUM CONCENTRATIONS OF DEFECTS IN Ti:SAPPHIRE}

As was already mentioned in the Introduction the equilibrium concentration of a given charged defect depends on the formation energies of all charged defects. If one considers the additional constraint (4) one should know the formation energies of all uncharged defects as well. In practice defect

TABLE II. Electrostatic correction $E_{i}^{(c)}$ to the defect formation energy for the $2 \times 2 \times 1$ supercell.

\begin{tabular}{lcc}
\hline \hline Defect & $q$ & $E_{i}^{(c)}(\mathrm{eV})$ \\
\hline $\mathrm{Ti}^{4+}$ & +1 & 0.11 \\
$\mathrm{~V}_{\mathrm{Al}}^{3-}$ & -3 & 1.21 \\
$\mathrm{Ti}^{4+}-\mathrm{V}_{\mathrm{Al}}^{3-}$ & -2 & 0.42 \\
$\mathrm{Ti}^{3+}-\mathrm{Ti}^{4+}$ & +1 & 0.05 \\
$\mathrm{Ti}^{4+}-\mathrm{Ti}^{4+}-\mathrm{V}_{\mathrm{Al}}^{3-}$ & -1 & 0.21 \\
$\mathrm{Ti}^{3+}-\mathrm{Ti}^{4+}-\mathrm{V}_{\mathrm{Al}}^{3-}$ & -2 & 0.68 \\
$\mathrm{Ti}^{3+}-\mathrm{Ti}^{3+}-\mathrm{V}_{\mathrm{Al}}^{3-}$ & -3 & 1.48 \\
$\mathrm{~F}_{\mathrm{O}}^{+}$ & +1 & 0.14 \\
$\mathrm{~F}_{\mathrm{O}}^{+}-\mathrm{V}_{\mathrm{Al}}^{3-}$ & -2 & 0.54 \\
$\mathrm{~F}_{\mathrm{O}}^{+}-\mathrm{F}_{\mathrm{O}}^{+}-\mathrm{V}_{\mathrm{Al}}^{3-}$ & -1 & 0.16 \\
$\mathrm{~N}_{\mathrm{O}}^{-}$ & -1 & 0.17 \\
$\mathrm{C}_{\mathrm{O}}^{2-}$ & -2 & 0.60 \\
$\mathrm{C}_{\mathrm{O}}^{-}$ & -1 & 0.15 \\
$\mathrm{C}_{\mathrm{O}}^{2-}-\mathrm{Ti}^{4+}$ & -1 & 0.16 \\
\hline \hline
\end{tabular}

species with large formation energies can be ignored since their contribution in Eqs. (3) and (4) is negligible.

We have calculated formation energies of different defects including substitutional and interstitial ions of Ti, C, N, and F in different charge states, native defects ( $\mathrm{Al}$ and $\mathrm{O}$ vacancies and interstitials), and complexes of such defects. We have found that most defects have rather large formation energies. We restrict our analysis with several defects species with the smallest formation energies. In the case of Ti:sapphire without codopants we consider three species of isolated defects $\left(\mathrm{Ti}^{3+}, \mathrm{Ti}^{4+}\right.$, and $\left.V_{\mathrm{Al}}^{3-}\right)$, three pairs $\left(\mathrm{Ti}^{3+}-\mathrm{Ti}^{3+}, \mathrm{Ti}^{3+}-\mathrm{Ti}^{4+}\right.$, and $\left.\mathrm{Ti}^{4+}-V_{\mathrm{Al}}^{3-}\right)$, four triples $\left(\mathrm{Ti}^{3+}-\mathrm{Ti}^{3+}-\mathrm{Ti}^{3+}, \mathrm{Ti}^{4+}-\mathrm{Ti}^{4+}-V_{\mathrm{Al}}^{3-}\right.$, $\mathrm{Ti}^{3+}-\mathrm{Ti}^{4+}-V_{\mathrm{Al}}^{3-}$, and $\left.\mathrm{Ti}^{3+}-\mathrm{Ti}^{3+}-V_{\mathrm{Al}}^{3-}\right)$, and a quadruple complex $\mathrm{Ti}^{4+}-\mathrm{Ti}^{4+}-\mathrm{Ti}^{4+}-V_{\mathrm{Al}}^{3-}$. For Ti:sapphire with codopants we add to this list two or three defect species (see below) formed by codopants.

In this section we concentrate on Ti:sapphire without codopants.

If the total number of $\mathrm{Ti}$ atoms is not fixed [the constraint (4) is not applied] the concentrations of charged defects are found from the following system of equations:

$$
\begin{gathered}
\tilde{n}_{4}^{3} \tilde{n}_{V}=e^{-\frac{3 E_{4}+E_{V}}{k_{\mathrm{B}} T}}, \\
\tilde{n}_{4}+2 C_{34} \tilde{n}_{3} \tilde{n}_{4}-3 \tilde{n}_{V}-8 C_{4 V} \tilde{n}_{4} \tilde{n}_{V}-18 C_{44 V} \tilde{n}_{4}^{2} \tilde{n}_{V} \\
-36 C_{34 V} \tilde{n}_{3} \tilde{n}_{4} \tilde{n}_{V}-54 C_{33 V} \tilde{n}_{3}^{2} \tilde{n}_{V}=0,
\end{gathered}
$$

where we use the notation $V \equiv V_{\mathrm{Al}}^{3-}$. In Eq. (27) we take into account the relation (9). The factors $C_{i_{c}}$ are the coefficients in the relation (9) averaged over different orientations and configurations:

$$
C_{i_{c}}=\frac{\sum_{f} K_{i_{c}, f} e^{\frac{E_{i_{c}, f}^{(b)}}{k_{\mathrm{B}} T}}}{\sum_{f} K_{i_{c}, f}},
$$

where $E_{i_{c}, f}^{(b)}$ is the binding energy of the complex $i_{c}$ and $K_{i_{c}, f}$ is the number of configurations and orientations with the same energy (different $f$ label configurations and orientations with distinct energies). Calculated binding energies and the numbers $K_{i_{c}, f}$ are given in Table III. Binding energies are independent of the chemical potentials of atoms. Binding energies given in Table III include the electrostatic correction $E_{i}^{(c)}$. They differ from ones calculated in Refs. [1,15], where this correction was not taken into account. The concentration of electrically neutral defects depends only on its own formation energy:

$$
\tilde{n}_{i}=e^{-\frac{E_{i}}{k_{\mathrm{B}} T}} .
$$

The formation energies of $\mathrm{Ti}^{3+}$ and of the electrically neutral combination of three $\mathrm{Ti}^{4+}$ and one $V_{\mathrm{Al}}^{3-}$ at $T=T_{m}$ are given in Table IV for all reference points of the Al-Ti-O phase diagram. Using Eqs. (26), (27), and (29) and the data from Tables III and IV we calculate $\tilde{n}_{3}, \tilde{n}_{4}$, and $\tilde{n}_{V}$. Concentrations of complex defects are found from Eq. (9) in which the factor $\exp \left(E_{i_{c}}^{(b)} / k_{\mathrm{B}} T\right)$ is replaced with the coefficient $C_{i_{c}}$, Eq. (28). The concentration of an $i$ th defect species is calculated as $c_{i}=$ $K_{i} \tilde{n}_{i} c_{\mathrm{Al}}$, where $c_{\mathrm{Al}}=4.7 \times 10^{22} \mathrm{~cm}^{-3}$ is the concentration of $\mathrm{Al}$ in the $\mathrm{Al}_{2} \mathrm{O}_{3}$ crystal, and $K_{i}=\sum_{f} K_{i, f}$ is the total number 
TABLE III. Binding energies $E_{i_{c}, f}^{(b)}$ and the numbers of different orientations and configurations $K_{i_{c}, f}$ with the same energy. Complexes of $\mathrm{Al}$ vacancy surrounded by two $\mathrm{Ti}$ and $\mathrm{Ti}$ surrounded by $\mathrm{Ti}$ and $\mathrm{Al}$ vacancy are notated as Ti- $V-\mathrm{Ti}$ and $\mathrm{Ti}-\mathrm{Ti}-V$, correspondingly. For complexes Ti-Ti-Ti- $V$ we consider only configurations with the vacancy in the center.

\begin{tabular}{|c|c|c|c|}
\hline Complex defect $i_{c}$ & Notation & $K_{i_{c}, f}$ & $E_{i_{c}, f}^{(b)}(\mathrm{eV})$ \\
\hline \multirow[t]{2}{*}{$\mathrm{Ti}^{3+}-\mathrm{Ti}^{3+}$} & 33 & 3 & 1.36 \\
\hline & 33 & 1 & 1.22 \\
\hline $\mathrm{Ti}^{3+}-\mathrm{Ti}^{3+}-\mathrm{Ti}^{3+}$ & 333 & 6 & 2.03 \\
\hline $\mathrm{Ti}^{4+}-\mathrm{Ti}^{4+}-\mathrm{Ti}^{4+}-V_{\mathrm{Al}}^{3-}$ & $444 \mathrm{~V}$ & 4 & 4.47 \\
\hline \multirow[t]{2}{*}{$\mathrm{Ti}^{3+}-\mathrm{Ti}^{4+}$} & 34 & 3 & 0.76 \\
\hline & 34 & 1 & 0.68 \\
\hline \multirow[t]{2}{*}{$\mathrm{Ti}^{4+}-V_{\mathrm{Al}}^{3-}$} & $4 \mathrm{~V}$ & 3 & 2.05 \\
\hline & $4 \mathrm{~V}$ & 1 & 1.85 \\
\hline \multirow[t]{2}{*}{$\mathrm{Ti}^{4+}-V_{\mathrm{Al}}^{3-}-\mathrm{Ti}^{4+}$} & $44 \mathrm{~V}$ & 3 & 3.36 \\
\hline & $44 \mathrm{~V}$ & 3 & 2.91 \\
\hline \multirow{2}{*}{$\mathrm{Ti}^{4+}-\mathrm{Ti}^{4+}-V_{\mathrm{Al}}^{3-}$} & $44 \mathrm{~V}$ & 6 & 2.51 \\
\hline & $44 \mathrm{~V}$ & 6 & 2.40 \\
\hline \multirow{2}{*}{$\mathrm{Ti}^{3+}-V_{\mathrm{Al}}^{3-}-\mathrm{Ti}^{4+}$} & $34 \mathrm{~V}$ & 3 & 2.69 \\
\hline & $34 \mathrm{~V}$ & 3 & 2.51 \\
\hline \multirow[t]{2}{*}{$\mathrm{Ti}^{3+}-\mathrm{Ti}^{4+}-V_{\mathrm{Al}}^{3-}$} & $34 \mathrm{~V}$ & 6 & 2.55 \\
\hline & $34 \mathrm{~V}$ & 6 & 2.49 \\
\hline $\mathrm{Ti}^{3+}-V_{\mathrm{Al}}^{3-}-\mathrm{Ti}^{3+}$ & $33 \mathrm{~V}$ & 6 & 0.92 \\
\hline $\mathrm{Ti}^{3+}-\mathrm{Ti}^{3+}-V_{\mathrm{Al}}^{3-}$ & $33 \mathrm{~V}$ & 12 & 1.88 \\
\hline \multirow[t]{2}{*}{$\mathrm{N}_{\mathrm{O}}^{-}-\mathrm{Ti}^{4+}$} & & 3 & 1.35 \\
\hline & & 3 & 1.10 \\
\hline $\mathrm{C}_{\mathrm{O}}^{2-}-\mathrm{Ti}^{4+}$ & & 6 & 2.95 \\
\hline \multirow[t]{2}{*}{$\mathrm{F}_{\mathrm{O}}^{+}-V_{\mathrm{Al}}^{3-}$} & $\mathrm{FV}$ & 3 & 1.61 \\
\hline & $\mathrm{FV}$ & 3 & 2.03 \\
\hline \multirow{4}{*}{$\mathrm{F}_{\mathrm{O}}^{+}-V_{\mathrm{Al}}^{3-}-\mathrm{F}_{\mathrm{O}}^{+}$} & FVF & 3 & 3.44 \\
\hline & FVF & 3 & 2.87 \\
\hline & FVF & 3 & 3.79 \\
\hline & FVF & 6 & 3.30 \\
\hline
\end{tabular}

of configurations and orientations of the $i$ th defect species $\left(K_{i}=1\right.$ for $\mathrm{Ti}^{3+}, \mathrm{Ti}^{4+}$, and $\left.V_{\mathrm{Al}}^{3-}\right)$.

The obtained equilibrium concentrations of defects and the overall concentration of $\mathrm{Ti}$ are shown in Fig. 3. To make this figure more readable we do not display the concentra- tion of $\mathrm{Ti}^{3+}-\mathrm{Ti}^{3+}-\mathrm{Ti}^{3+}$ triples, which is lower than that of $\mathrm{Ti}^{3+}-\mathrm{Ti}^{3+}$ pairs. The concentrations of the $\mathrm{Ti}^{3+}-\mathrm{Ti}^{3+}-V_{\mathrm{Al}}^{3-}$ and $\mathrm{Ti}^{3+}-\mathrm{Ti}^{4+}-V_{\mathrm{Al}}^{3-}$ complexes are not displayed either. They are generally much lower than the concentration of $\mathrm{Ti}^{4+}-\mathrm{Ti}^{4+}-V_{\mathrm{Al}}^{3-}$ complexes (they are comparable only in the reduced conditions).

One can see from Fig. 3 that the overall concentration of $\mathrm{Ti}$ varies in the range from $6 \times 10^{19} \mathrm{~cm}^{-3}$ to $3.5 \times 10^{20} \mathrm{~cm}^{-3}$ that corresponds to the range from 0.12 wt. $\%$ to 0.7 wt. $\%$ of Ti. This concentration is rather high. For instance, in samples investigated in Ref. [13] the concentration of $\mathrm{Ti}$ was in the range from 0.006 to 0.2 wt.\%. Samples used in Refs. [3-5,8,11] had the concentration of Ti less than 0.1 wt.\%. The concentration of Ti in samples grown in Ref. [6] was in the range from 0.1 to $0.25 \mathrm{wt} . \%$.

If the total concentration of Ti differs from the equilibrium one we should take into account the constraint (4). Then we arrive at a system of three equations:

$$
\begin{gathered}
\tilde{n}_{4}^{3} \tilde{n}_{V}=\tilde{n}_{3}^{3} e^{\frac{3 E_{3}-3 E_{4}-E_{V}}{k_{\mathrm{B}} T}}, \\
\tilde{n}_{4}+2 C_{34} \tilde{n}_{3} \tilde{n}_{4}-3 \tilde{n}_{V}-8 C_{4 V} \tilde{n}_{4} \tilde{n}_{V}-18 C_{44 V} \tilde{n}_{4}^{2} \tilde{n}_{V} \\
-36 C_{34 V} \tilde{n}_{3} \tilde{n}_{4} \tilde{n}_{V}-54 C_{33 V} \tilde{n}_{3}^{2} \tilde{n}_{V}=0, \\
\tilde{n}_{3}+\tilde{n}_{4}+4 C_{34} \tilde{n}_{3} \tilde{n}_{4}+4 C_{33} \tilde{n}_{3}^{2}+18 C_{333} \tilde{n}_{3}^{3} \\
+4 C_{4 V} \tilde{n}_{4} \tilde{n}_{V}+36 C_{44 V} \tilde{n}_{4}^{2} \tilde{n}_{V}+36 C_{34 V} \tilde{n}_{3} \tilde{n}_{4} \tilde{n}_{V} \\
+36 C_{33 V} \tilde{n}_{3}^{2} \tilde{n}_{V}+12 C_{444 V} \tilde{n}_{4}^{3} \tilde{n}_{V}=\frac{n_{\mathrm{Ti}}}{n_{\mathrm{Al}}} .
\end{gathered}
$$

The quantity $3 E_{3}-3 E_{4}-E_{V}$ in Eq. (30) and the coefficients $C_{i_{c}}$ in Eqs. (31) and (32) are independent of $\mu_{\mathrm{Ti}}$. Consequently, the solution of the system (30)-(32) is also independent of $\mu_{\mathrm{Ti}}$ and concentrations can be presented as continuous functions of $\mu_{\mathrm{O}}$. The oxygen chemical potential varies in the range $\left[\mu_{\mathrm{r}}, \mu_{\mathrm{o}}\right]$, where $\mu_{\mathrm{r}}=\left[\mu\left(\mathrm{Al}_{2} \mathrm{O}_{3}\right)-2 \mu(\mathrm{Al})\right] / 3$ ( $\left.\mu_{\mathrm{o}}=\mu\left(\mathrm{O}_{2}\right) / 2\right)$ is the value of the oxygen chemical potential in the reduced (oxidized) limit. The boundaries $\mu_{\mathrm{r}}$ and $\mu_{\mathrm{o}}$ depend on temperature.

\begin{tabular}{|c|c|c|c|c|c|c|}
\hline Point & $E_{3}$ & $\left(3 E_{4}+E_{V}\right) / 4$ & $\left(E_{4}+E_{\mathrm{N}_{\mathrm{O}}^{-}}\right) / 2$ & $\left(2 E_{4}+E_{\mathrm{C}_{\mathrm{O}}^{2-}}\right) / 3$ & $\left(E_{4}+E_{\mathrm{C}_{\mathrm{O}}^{-}}\right) / 2$ & $E_{\mathrm{F}_{\mathrm{O}}^{+}}-E_{4}$ \\
\hline A & 2.25 & 1.57 & 3.21 & 5.64 & 7.24 & 0.29 \\
\hline B & 1.71 & 1.57 & 2.40 & 4.19 & 5.33 & 0.29 \\
\hline $\mathrm{C}$ & 1.57 & 1.79 & & 3.23 & 3.97 & \\
\hline $\mathrm{D}$ & 1.48 & 1.92 & 1.59 & 2.83 & 3.41 & -0.17 \\
\hline E & 1.48 & 1.96 & 1.53 & & & \\
\hline $\mathrm{F}$ & 1.48 & 2.03 & & 2.62 & 3.09 & \\
\hline G & 1.92 & 2.43 & & 2.80 & 3.14 & \\
\hline $\mathrm{H}$ & 2.11 & 2.59 & 1.64 & & & \\
\hline I & 1.48 & 2.14 & 1.65 & 2.67 & 3.17 & -0.47 \\
\hline $\mathrm{J}$ & 1.52 & 2.21 & 1.68 & 2.70 & 3.19 & -0.56 \\
\hline $\mathrm{K}$ & 2.11 & 2.65 & 1.68 & & & \\
\hline $\mathrm{L}$ & 2.23 & 2.74 & & 2.94 & 3.19 & \\
\hline
\end{tabular}

Calculated concentrations of simple and paired defects at a fixed overall concentration of $\mathrm{Ti}\left(c_{\mathrm{Ti}}\right)$ are presented in Fig. 4. We consider three different $c_{\mathrm{Ti}}\left(10^{20} \mathrm{~cm}^{-3}, 10^{19} \mathrm{~cm}^{-3}\right.$, and

TABLE IV. Defect formation energies (in eV) at reference points of Al-Ti-O and Al-Ti-O- $X(X=\mathrm{C}, \mathrm{N}, \mathrm{F})$ phase diagram at $T=T_{m}$. The energies of electrically neutral combinations are given per one defect. 

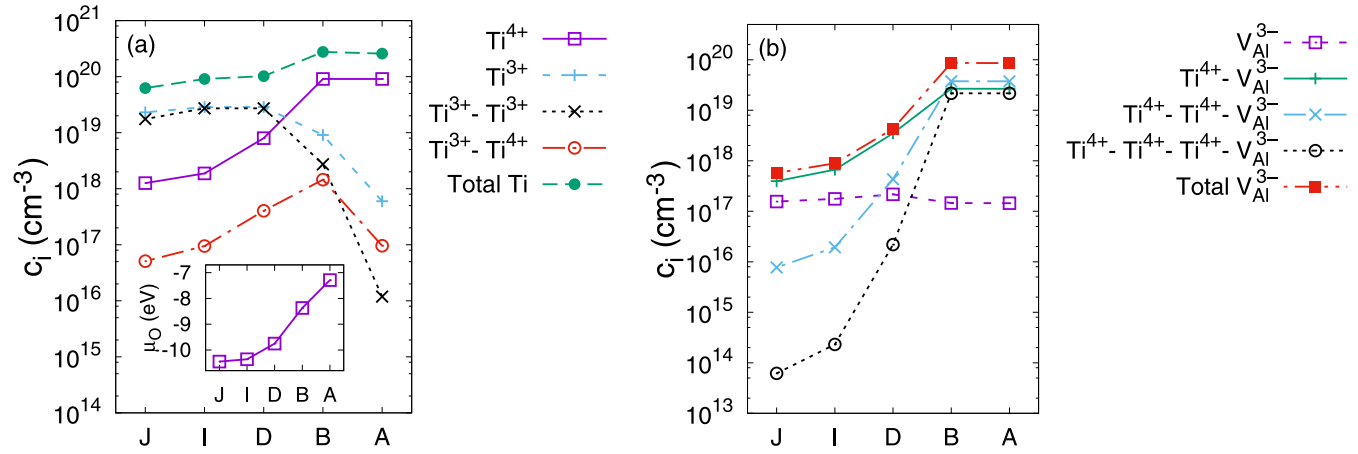

FIG. 3. Equilibrium concentration of isolated $\mathrm{Ti}^{3+}$ and $\mathrm{Ti}^{4+}$ defects, $\mathrm{Ti}^{3+}-\mathrm{Ti}^{3+}$ and $\mathrm{Ti}^{3+}-\mathrm{Ti}^{4+}$ pairs, and total concentration of $\mathrm{Ti}^{\mathrm{a}}(\mathrm{a})$ and concentration of isolated $V_{\mathrm{Al}}^{3-}$ vacancies, complexes of $V_{\mathrm{Al}}^{3-}$ vacancy with one, two, and three $\mathrm{Ti}^{4+}$, and total concentration of $V_{\mathrm{Al}}^{3-}$ vacancies (b) in Ti:sapphire at $T=T_{m}$ in the conditions that correspond to reference points of Al-Ti-O phase diagram Fig. 1 (see also Table I). Lines are guides to the eye. Oxygen chemical potential is given in the inset in panel (a).

$10^{18} \mathrm{~cm}^{-3}$ ) and two temperatures: $T=T_{m}=2327 \mathrm{~K}$ and $T=T_{a}=2000 \mathrm{~K}$. We consider that $T=T_{m}$ concentrations correspond to as-grown samples and $T=T_{a}<T_{m}$ ones, to samples annealed at $T=T_{a}$. One can see from Fig. 5 that annealing may result in an increase or a decrease of the concentration of a given defect species depending on the oxygen
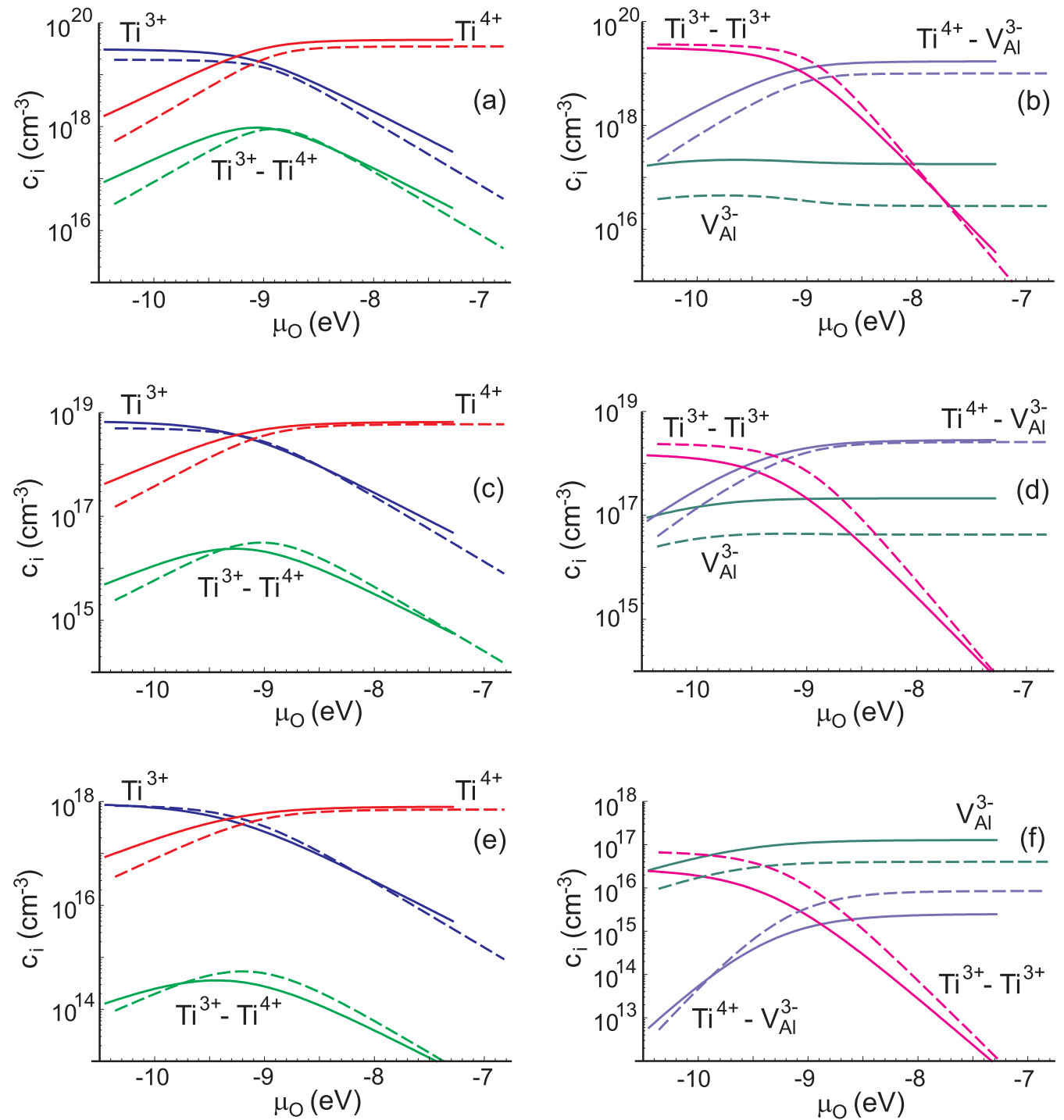

FIG. 4. Equilibrium concentrations of isolated and paired defects at $T=2327 \mathrm{~K}$ (solid curves) and $T=2000 \mathrm{~K}$ (dashed curves) at fixed overall concentration of Ti $c_{\mathrm{Ti}}=10^{20} \mathrm{~cm}^{-3}[(\mathrm{a}),(\mathrm{b})], c_{\mathrm{Ti}}=10^{19} \mathrm{~cm}^{-3}[(\mathrm{c}),(\mathrm{d})]$, and $c_{\mathrm{Ti}}=10^{18} \mathrm{~cm}^{-3}$ [(e), (f)]. 


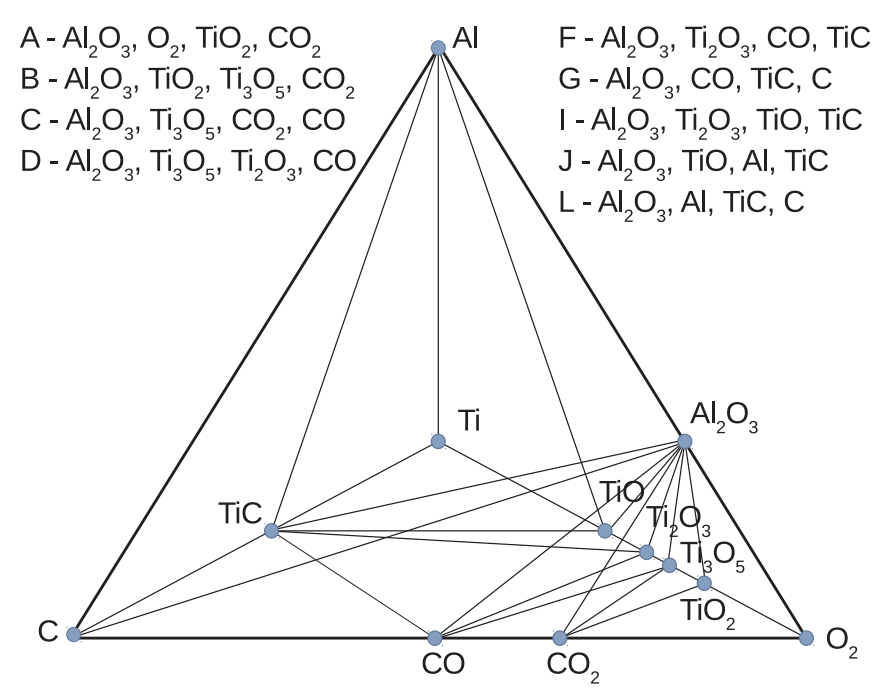

FIG. 5. The phase diagram of the Al-Ti-O-C system at $T=T_{m}$ and reference points.

chemical potential and the total concentration of Ti. As was expected, a relative fraction of isolated defects increases under lowering in the total concentration of Ti.

\section{CONCENTRATION OF DEFECTS IN Ti:SAPPHIRE GROWN IN THE PRESENCE OF CARBON, NITROGEN, FLUORINE, AND THEIR COMPOUNDS}

To obtain crystals with a low concentration of $\mathrm{Ti}^{4+}$ and high FOM it is desirable to grow them in the reduced conditions. To do that one can add certain substances or compounds to the melt or to the atmosphere or anneal samples in their presence. A side effect of such a treatment is codoping of Ti:sapphire. Charged defects formed by dopants may change a balance between different $\mathrm{Ti}$ defects which results in a change of the ratio of concentration of isolated $\mathrm{Ti}^{3+}$ ions to the concentration of $\mathrm{Ti}^{3+}-\mathrm{Ti}^{4+}$ pairs. The mechanism is quite simple. If codoping results in an appearance of additional positively charged defects, some negatively charged vacancies $V_{\mathrm{Al}}^{3-}$ compensate codopants and the concentration of $\mathrm{Ti}^{4+}$ decreases. Consequently, according to Eq. (11) (valid for codoped samples, as well) the ratio $c_{\mathrm{Ti}^{3+}} / c_{\mathrm{Ti}^{3+}{ }^{3} i^{4+}}$ increases. If codoping results in the appearance of additional negatively charged defects, the concentration of isolated $\mathrm{Ti}^{4+}$ ions increases to provide charge compensation. Consequently, the ratio $c_{\mathrm{Ti}^{3+}} / c_{\mathrm{Ti}^{3+} \mathrm{Ti}^{4+}}$ decreases. To determine the role of a given codopant one should take into account not only isolated charged defects formed by codopant atoms but complex defects as well. Among such complex defects it is important to consider pairs and triples formed by codopants with vacancies $V_{\mathrm{Al}}^{3-}$ and with $\mathrm{Ti}^{4+}$.

In addition to a shift of the charge balance, codoping may create additional impurity levels in the band gap that will influence optical properties of crystals.

In this section we consider codoping of Ti:sapphire with carbon, nitrogen, and fluorine.

\section{A. Al-Ti-O-C system}

Using calculated heats of formation of relevant materials we build the four-component Al-Ti-O-C phase diagram (Fig. 5). The calculations were done for graphite phase of carbon. There are nine points at the diagram Fig. 5 (labeled as $\mathrm{A}, \mathrm{B}, \mathrm{C}, \mathrm{D}, \mathrm{F}, \mathrm{G}, \mathrm{I}, \mathrm{J}, \mathrm{L}$ ), where $\mathrm{Al}_{2} \mathrm{O}_{3}$ is in equilibrium with three other phases.

We have calculated the formation energies of substitutional $\mathrm{C}_{\mathrm{O}}$ and $\mathrm{C}_{\mathrm{Al}}$ defects and carbon interstitial in different charge states. Most of these energies are quite large. In the intermediate and reduced conditions two substitutional defects, $\mathrm{C}_{\mathrm{O}}^{2-}$ and $\mathrm{C}_{\mathrm{O}}^{-}$, dominate. Negatively charged carbon defects may bind in pairs and triples with $\mathrm{Ti}^{4+}$ and $\mathrm{Ti}^{3+}$. Binding energies of such complexes are large and complex defects prevail over isolated ones. Among complex defects the concentration of $\mathrm{C}_{\mathrm{O}}^{2-}-\mathrm{Ti}^{4+}$ pairs is the highest one. It can reach the level of $10^{16} \mathrm{~cm}^{-3}$. But since the concentration of isolated $\mathrm{Ti}^{4+}$ is at least two orders higher, carbon defects practically do not influence the concentration of $\mathrm{Ti}^{4+}$ and $\mathrm{Ti}^{3+}-\mathrm{Ti}^{4+}$.

Our results correlate with ones obtained for $\mathrm{C}$-doped $\alpha-\mathrm{Al}_{2} \mathrm{O}_{3}$ in Refs. [27-29], where the formation energies of substitutional and interstitial carbon defects were calculated. It was shown in Refs. [27-29] that in the reduced conditions the substitutional $\mathrm{C}_{\mathrm{O}}$ defects have the smallest formation energy, while in the oxidized conditions the substitutional $\mathrm{C}_{\mathrm{Al}}$ defects are energetically preferable. The formation energies of interstitial carbon defects are large both in the reduced and in the oxidized conditions. Here we do not consider $\mathrm{C}_{\mathrm{Al}}$ but find that in the oxidized conditions the concentrations of $\mathrm{C}_{\mathrm{O}}$ are extremely low ones (see Fig. 7 below). We cannot compare directly the results of [27-29] with our results since in Refs. [27-29] the chemical potential of C was set to be the same as in diamond [27] or in graphite [28,29] irrespective of the value of the oxygen chemical potential.

In Fig. 6 we display equilibrium concentrations of Ti defects and Al vacancies at the reference points of the Al-Ti-O-C phase diagram at $T=T_{m}$. The concentrations are obtained from Eqs. (26) and (27), where we neglect the contribution of carbon defects.

The concentrations of carbon defects are found from the relations

$$
\tilde{n}_{\mathrm{C}_{\mathrm{O}}^{-}}=\frac{e^{-\frac{{ }_{\mathrm{C}_{\mathrm{O}}^{-}}+E_{4}}{k_{\mathrm{B}} T}}}{\tilde{n}_{4}}, \quad \tilde{n}_{\mathrm{C}_{\mathrm{O}}^{2-}}=\frac{e^{-\frac{{ }_{{ }_{\mathrm{C}}}^{2-}+2 E_{4}}{k_{\mathrm{B}} T}}}{\left(\tilde{n}_{4}\right)^{2}} .
$$

Equations (33) are obtained from Eq. (5) (with $\lambda_{\mathrm{Ti}}=0$ ). The concentration of pairs $\mathrm{C}_{\mathrm{O}}^{2-}-\mathrm{Ti}^{4+}$ is found from Eq. (9). The energies $\left(E_{\mathrm{C}_{\mathrm{O}}^{-}}+E_{4}\right) / 2$ and $\left(E_{\mathrm{C}_{\mathrm{O}}^{-}}+2 E_{4}\right) / 3$ are given in Table IV, and the binding energy of the $\mathrm{C}_{\mathrm{O}}^{2-}-\mathrm{Ti}^{4+}$ pair, in Table III. Calculated concentrations of carbon defects are shown in Fig. 7.

\section{B. Al-Ti-O-N system}

In Fig. 8 we present the Al-Ti-O-N phase diagram at $T=$ $T_{m}$ that was built using calculated heats of formation of related materials. This diagram contains eight reference points (A, B, D, E, H, I, J, K). The formation energy of $\mathrm{N}_{\mathrm{O}}^{-}$defects 

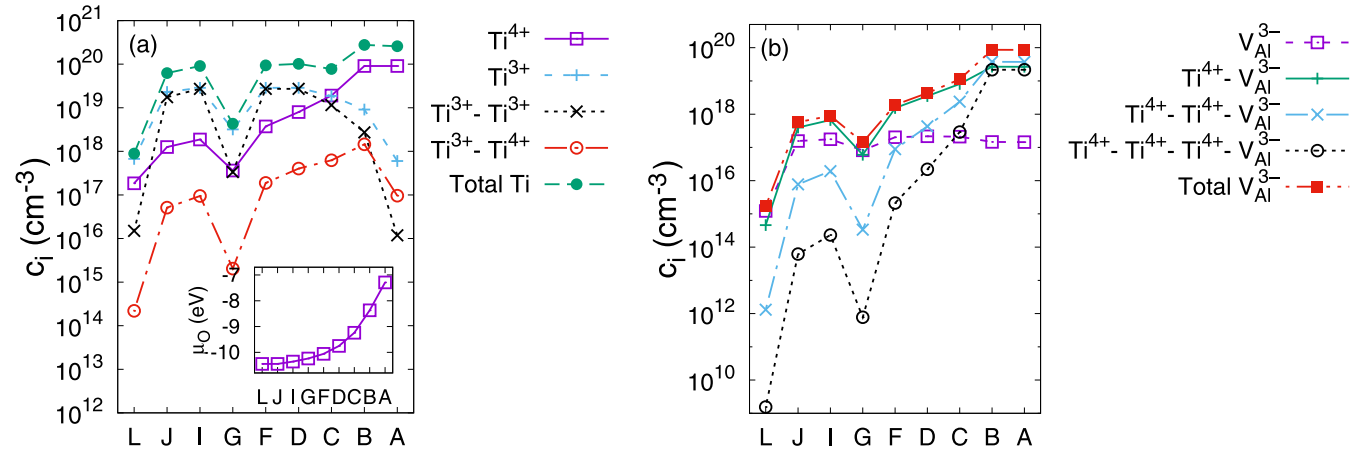

FIG. 6. Equilibrium concentrations of defects in Ti:sapphire at $T=T_{m}$ in the conditions that correspond to reference points of Al-Ti-O-C phase diagram Fig. 5. Defect species in panels (a) and (b) are the same as in Figs. 3(a) and 3(b). Oxygen chemical potential is given in the inset in the panel (a).

is small and their concentration is high. It correlates with the results of [27] where the formation energies of nitrogen defects in $\mathrm{Al}_{2} \mathrm{O}_{3}$ were calculated. It was shown [27] that even in the oxidized conditions the substitutional $\mathrm{N}_{\mathrm{O}}^{-}$defect has the smallest formation energy. The $\mathrm{N}_{\mathrm{O}}^{-}$defects shift the balance between other charged defects in Ti:sapphire. To evaluate this shift we add the term $-(3 / 2) \tilde{n}_{\mathrm{N}}$ to the left-hand side of Eq. (27), where $\tilde{n}_{\mathrm{N}}$, is the number of $\mathrm{N}_{\mathrm{O}}^{-}$defects normalized to the total number of oxygen atoms. The quantity $\tilde{n}_{\mathrm{N}}$ is expressed through $\tilde{n}_{4}$ using Eq. (5) with $\lambda_{\mathrm{Ti}}=0$ :

$$
\tilde{n}_{\mathrm{N}}=\frac{e^{-\frac{E_{\mathrm{N}^{-}}+E_{4}}{k_{\mathrm{B}} T}}}{\tilde{n}_{4}} .
$$

The energy $\left(E_{\mathrm{N}_{0}^{-}}+E_{4}\right) / 2$ is given in Table IV. In Fig. 9 we present calculated concentrations of $\mathrm{Ti}$ defects and $\mathrm{Al}$ vacancies at $T=T_{m}$ at the reference points of the Al-Ti-O-N phase diagram. One can see that the presence of nitrogen defects results in a considerable increase of the concentration of $\mathrm{Ti}^{4+}$ and in an increase of the overall concentration of $\mathrm{Ti}$ in the reduced and intermediate condition.

Negatively charged nitrogen defects can bind in pairs with $\mathrm{Ti}^{4+}$. The binding energy of such a pair is given in Table III. The calculated concentration of isolated $\mathrm{N}_{\mathrm{O}}^{-}$defects

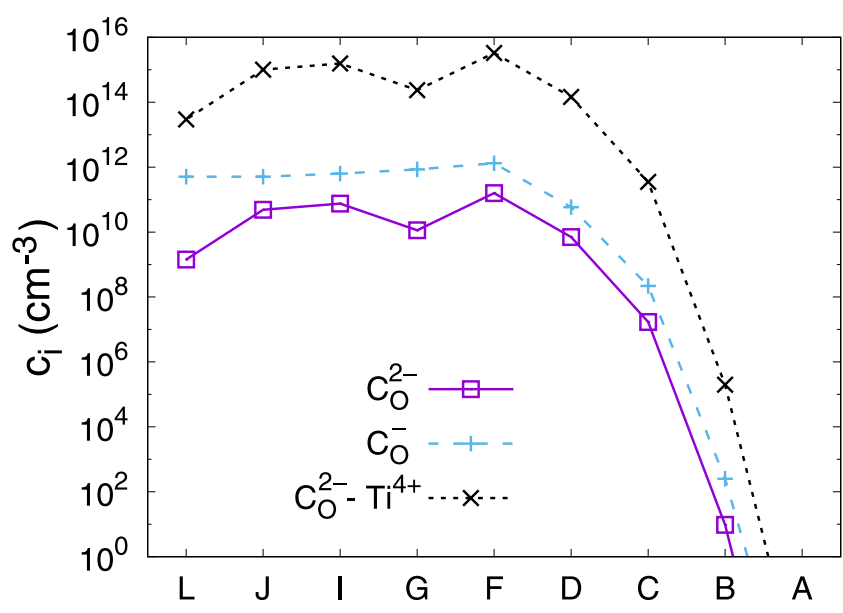

FIG. 7. Equilibrium concentrations of carbon defects at $T=T_{m}$. Lines are guides to the eye. and $\mathrm{N}_{\mathrm{O}}^{-}-\mathrm{Ti}^{4+}$ pairs and the total concentration of nitrogen are shown in Fig. 10. In the oxidized conditions the concentration of nitrogen defects decreases and they do not influence the concentration of $\mathrm{Ti}^{4+}$. The concentration of $\mathrm{N}_{\mathrm{O}}^{-} \mathrm{Ti}^{4+}$ pairs is slightly higher than the concentration of isolated $\mathrm{N}_{\mathrm{O}}^{-}$defects, but since these pairs are electrically neutral, they do not influence the concentration of charged defects.

The increase in the concentration of $\mathrm{Ti}^{3+}-\mathrm{Ti}^{4+}$ pairs results in a decrease of the $c_{\mathrm{Ti}^{3+}} / c_{\mathrm{Ti}^{3+}-\mathrm{Ti}^{4+}}$ ratio and a decrease of the FOM.

\section{Al-Ti-O-F system}

Keeping in mind that fluorine ions enter into Ti:sapphire mostly in the form of substitutional $\mathrm{F}_{\mathrm{O}}^{+}$defects one would expect that codoping with fluorine decreases the concentration of $\mathrm{Ti}^{4+}$. But the situation appears to be more complicated due to formation of negatively charged complexes of $\mathrm{F}_{\mathrm{O}}^{+}$and $V_{\mathrm{Al}}^{3-}$.

The calculated four-component Al-Ti-O-F phase diagram at $T=T_{m}$ is shown in Fig. 11. This diagram contains five reference points (A, B, D, I, J). In all these points $\mathrm{Al}_{2} \mathrm{O}_{3}$ is in equilibrium with $\mathrm{AlF}_{3}$. Two other compounds are the same as for the reference points of the Al-Ti-O diagram (Fig. 1).

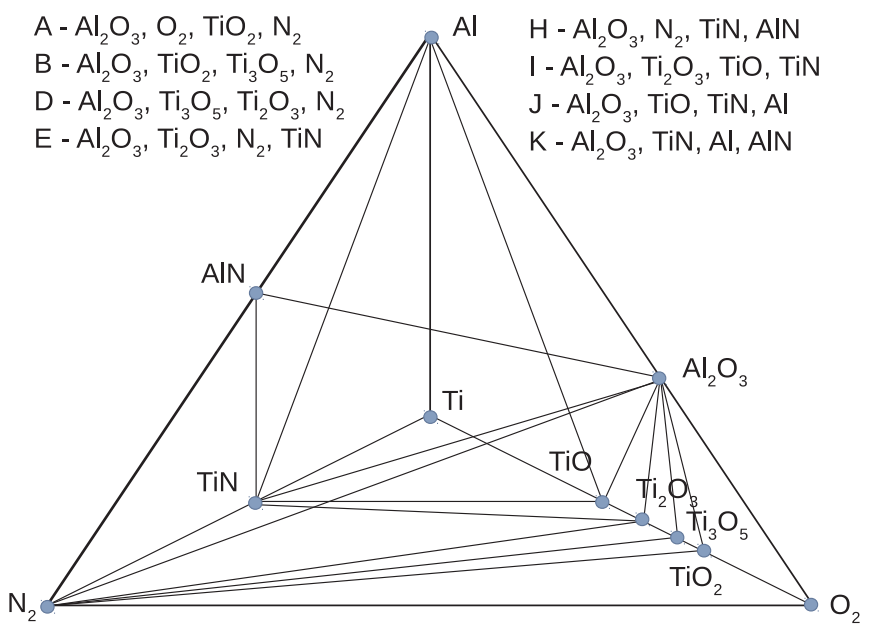

FIG. 8. The phase diagram of the Al-Ti-O-N system at $T=T_{m}$ and reference points. 

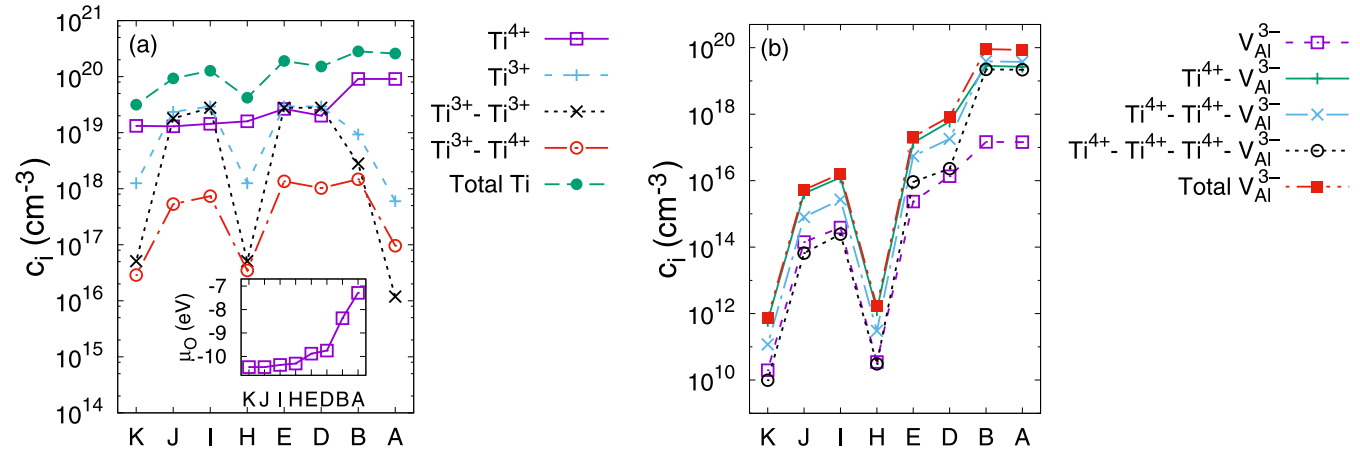

FIG. 9. Equilibrium concentrations of defects in Ti:sapphire at $T=T_{m}$ in the conditions that correspond to reference points of Al-Ti-O-N phase diagram Fig. 8. Defect species in panels (a) and (b) are the same as in Figs. 3(a) and 3(b). Oxygen chemical potential is given in the inset in panel (a).

Calculations show that together with positively charged $\mathrm{F}_{\mathrm{O}}^{+}$ defects two types of negatively charged complexes formed by fluorine have small formation energies. They are the pairs $\mathrm{F}_{\mathrm{O}}^{+}-V_{\mathrm{Al}}^{3-}$ and the triples $\mathrm{F}_{\mathrm{O}}^{+}-\mathrm{F}_{\mathrm{O}}^{+}-V_{\mathrm{Al}}^{3-}$. To calculate equilibrium concentrations of defects we take into account three fluorine defect species and add to the left-hand part of Eq. (27) the terms $(3 / 2) \tilde{n}_{\mathrm{F}}-12 C_{\mathrm{F} V} \tilde{n}_{\mathrm{F}} \tilde{n}_{V}-15 C_{\mathrm{F} V \mathrm{~F}} \tilde{n}_{\mathrm{F}}^{2} \tilde{n}_{V}$, where $\tilde{n}_{\mathrm{F}}$ is the number of $\mathrm{F}_{\mathrm{O}}^{+}$defects normalized to the total number of oxygen atoms. The quantities $\tilde{n}_{\mathrm{F}}$ and $\tilde{n}_{4}$ satisfy the equation

$$
\tilde{n}_{\mathrm{F}}=\tilde{n}_{4} e^{-\frac{{ }_{\mathrm{F}_{+}^{+}}-E_{4}}{k_{\mathrm{B}} T}}
$$

which follows from Eq. (5). The difference $E_{\mathrm{F}_{\mathrm{O}}^{+}}-E_{4}$ is given in Table IV. The binding energies of the complexes $\mathrm{F}_{\mathrm{O}}^{+}-V_{\mathrm{Al}}^{3-}$ and $\mathrm{F}_{\mathrm{O}}^{+}-\mathrm{F}_{\mathrm{O}}^{+}-V_{\mathrm{Al}}^{3-}$ are presented in Table III.

The calculated equilibrium concentrations of defects are shown in Figs. 12 and 13. One can see from Fig. 13 that the concentrations of positively charged $\mathrm{F}_{\mathrm{O}}^{+}$and negatively charged $\mathrm{F}_{\mathrm{O}}^{+}-\mathrm{F}_{\mathrm{O}}^{+}-V_{\mathrm{Al}}^{3-}$ are close to each other. Negatively charged defects almost compensate positively charged ones and the concentrations of $\mathrm{Ti}^{4+}$ and $\mathrm{Ti}^{3+}-\mathrm{Ti}^{4+}$ are changed unessentially. Thus, our expectation on a positive role of fluorine is not confirmed. It appears that triples $\mathrm{F}_{\mathrm{O}}^{+}-\mathrm{F}_{\mathrm{O}}^{+}-V_{\mathrm{Al}}^{3-}$ have rather small formation energy and the positive effect caused by isolated $\mathrm{F}_{\mathrm{O}}^{+}$ions reduces due to formation of $\mathrm{F}_{\mathrm{O}}^{+}-\mathrm{F}_{\mathrm{O}}^{+}-V_{\mathrm{Al}}^{3-}$

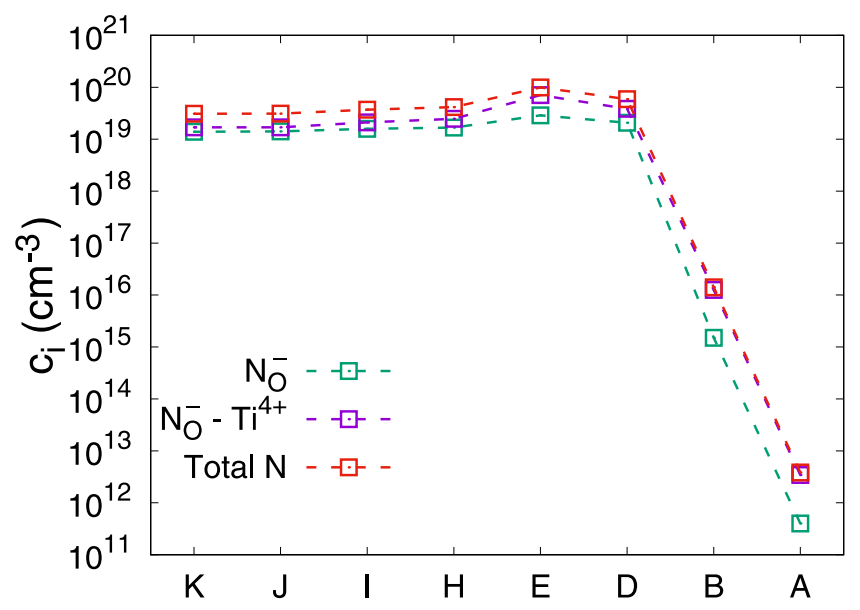

FIG. 10. Equilibrium concentrations of nitrogen defects at $T=T_{m}$. triples. We note that such a reduction is not a general rule. It would not happen if the binding energy of complexes was smaller.

\section{Influence of codoping on the FOM}

To determine the impact of carbon, nitrogen, and fluorine compounds on the FOM of Ti:sapphire we calculate the $c_{\mathrm{Ti}^{3+}} / c_{\mathrm{Ti}^{3+}-\mathrm{T}^{4+}}$ ratio at all reference points of Table I using the data presented in Figs. 6, 9, and 12. The result is shown in Fig. 14. Since the concentration of carbon defects is low, at the points A, B, D, I, J the result is the same for Al-Ti-O-C and $\mathrm{Al}-\mathrm{Ti}-\mathrm{O}$ systems. At the same time under conditions that corresponds to the points $\mathrm{G}$ and $\mathrm{L}$ one can to reach the much larger ratio of $c_{\mathrm{Ti}^{3+}} / c_{\mathrm{Ti}^{3+}-\mathrm{Ti}^{4+}}$. The latter is connected with the low total equilibrium concentration of $\mathrm{Ti}$ at these points. This conclusion is in agreement with experimental study [30] where it was shown that thermal carbon treatment of raw materials $\left(\mathrm{Al}_{2} \mathrm{O}_{3}\right.$ and $\left.\mathrm{TiO}_{2}\right)$ makes it possible to decrease the concentration of $\mathrm{Ti}^{4+}$ in Ti: $\mathrm{Al}_{2} \mathrm{O}_{3}$ crystals. With this, Fig. 14 illustrates that nitrogenization provokes considerable reduction of the $c_{\mathrm{Ti}^{3+}} / c_{\mathrm{Ti}^{3+}-\mathrm{Ti}^{4+}}$ ratio in the reduced and intermediate conditions, and that fluoridization leaves this ratio almost unchanged.

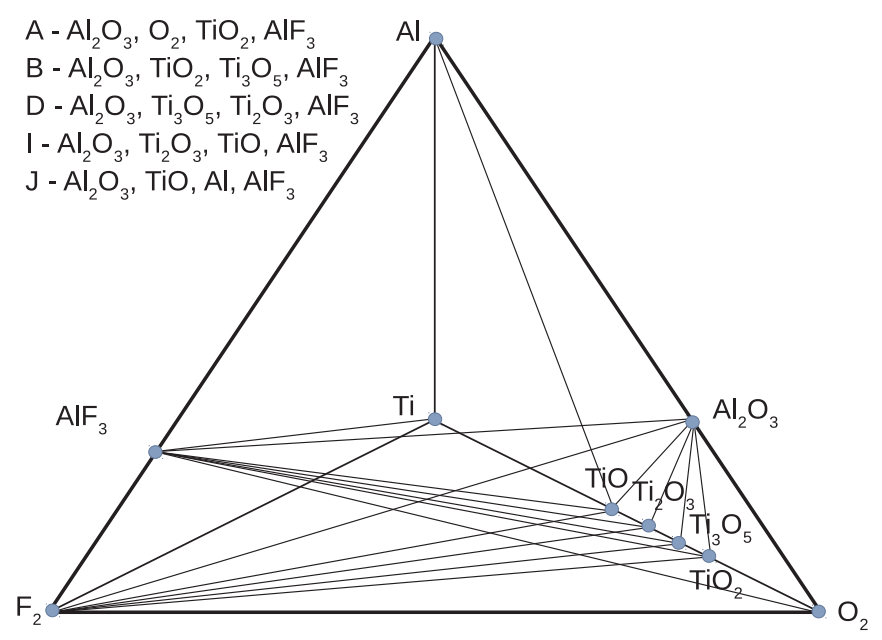

FIG. 11. The phase diagram of the Al-Ti-O-F system at $T=T_{m}$ and reference points. 

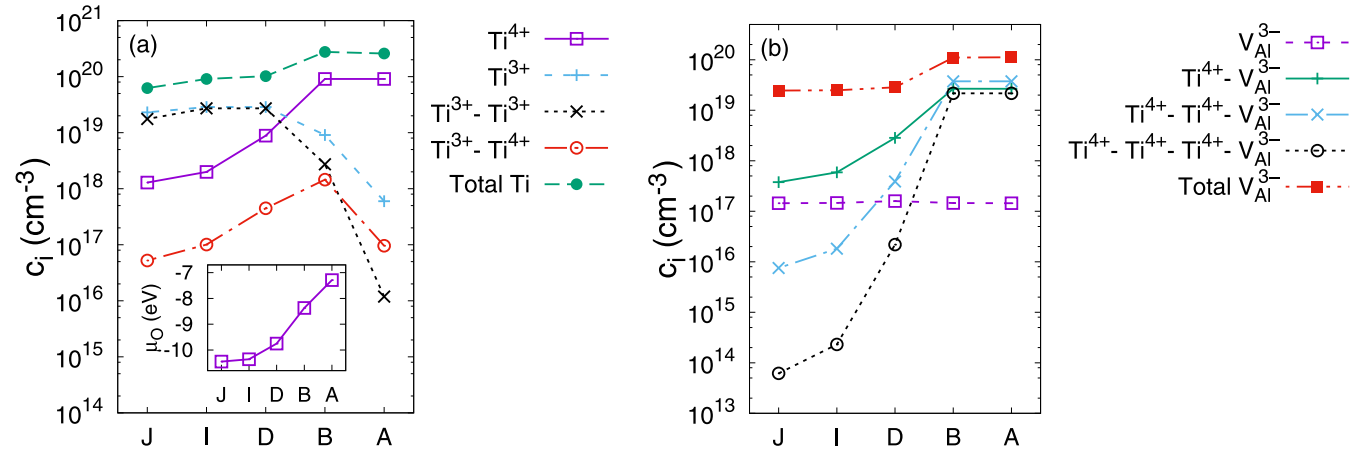

FIG. 12. Equilibrium concentrations of defects in Ti:sapphire at $T=T_{m}$ in the conditions that correspond to reference points of Al-Ti-O-F phase diagram Fig. 11. Defect species in panels (a) and (b) are the same as in Figs. 3(a) and 3(b). Oxygen chemical potential is given in the inset in panel (a).

It is instructive to evaluate the relation between the FOM and $c_{\mathrm{Ti}^{3+}} / c_{\mathrm{Ti}^{3+}-\mathrm{Ti}^{4+}}$. To do that we use the data of [13]. One of the samples investigated in Ref. [13] (labeled as SY1b) had $\mathrm{FOM}=12$. Concentrations of $\mathrm{Ti}^{3+}$ and $\mathrm{Ti}^{4+}$ in this sample were estimated as $1.3 \times 10^{18} \mathrm{~cm}^{-3}$ and $2.3 \times 10^{18} \mathrm{~cm}^{-3}$, correspondingly. Using Eq. (11) and taking $T=2000 \mathrm{~K}$ we obtain $c_{\mathrm{Ti}^{3+}-\mathrm{Ti}^{4+}} \approx 10^{16} \mathrm{~cm}^{-3}$ and $c_{\mathrm{Ti}^{3+}} / c_{\mathrm{Ti}^{3+}-\mathrm{Ti}^{4+}} \approx 100$. Thus one can estimate that FOM $\sim 0.1 \times c_{\mathrm{Ti}^{3+}} / c_{\mathrm{Ti}^{3+}-\mathrm{Ti}^{4+}}$. Note that, normally, commercial samples have FOM $=100-300$ and FOM of the best samples is up to 1000 .

\section{E. Band structure of Ti:sapphire codoped with carbon, nitrogen, and fluorine}

Codoping may result in the appearance of additional defect levels in the band gap. To consider this effect we calculate the band structure of the system with one given defect per supercell. Strictly speaking, from such calculations one obtains impurity bands of a crystal with periodically arranged defects. But since such bands are very narrow they can be associated with impurity levels connected with a given defect. The position of obtained impurity levels in the band gap and separation between them weakly depend on the supercell

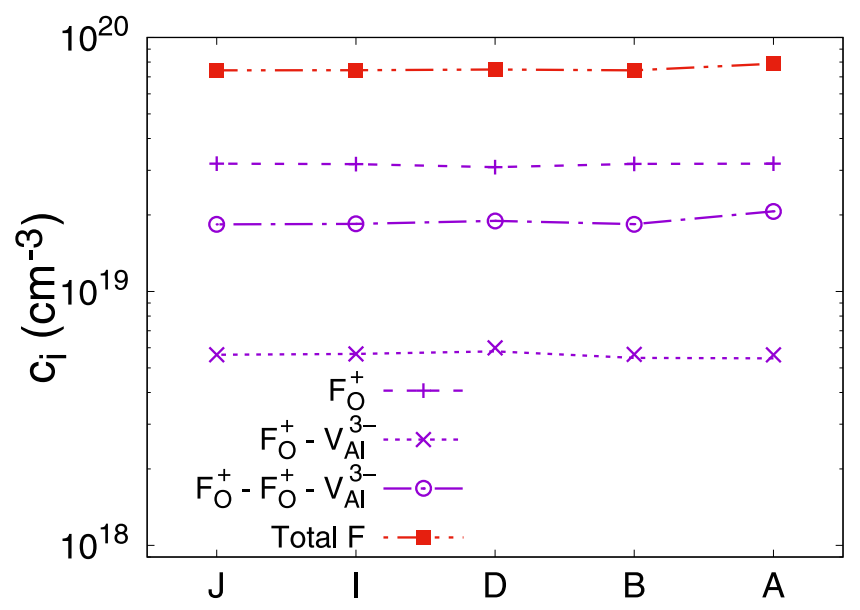

FIG. 13. Equilibrium concentrations of fluorine defects at $T=T_{m}$. size. This can be seen from comparison of the results of Refs. [31,32] and our calculations [1].

In Figs. 15-17 we present the band structure of a sapphire crystal with carbon, nitrogen, and fluorine defects. For comparison, in Figs. 15(d) and 17(d) we reproduce the band structures of crystals with $\mathrm{Ti}^{4+}$ substitutional defects and with $V_{\mathrm{Al}}^{3-}$ vacancies [1]. One can see that fluorine defects do not cause additional impurity levels in the band gap. Formation of complexes of fluorine defects with Al vacancy results in a minor modification of $\mathrm{Al}$ vacancy levels. In contrast, negatively charged carbon and nitrogen defects $\left(\mathrm{C}_{\mathrm{O}}^{2-}, \mathrm{C}_{\mathrm{O}}^{-}\right.$, and $\mathrm{N}_{\mathrm{O}}^{-}$) reveal themselves in an appearance of additional impurity levels. Binding of such defects with $\mathrm{Ti}^{4+}$ causes splitting of $\mathrm{Ti}$ impurity levels.

Due to small equilibrium concentration of carbon defects one can expect that carbon impurities will not influence significantly optical properties of Ti:sapphire. Equilibrium concentration of nitrogen defects is much higher. Therefore growth or annealing in the presence of nitrogen compounds may result in an essential modification of optical properties of Ti:sapphire not only due to a change of the balance between $\mathrm{Ti}^{3+}$ and $\mathrm{Ti}^{4+}$ ions, but also due to the appearance of impurity levels caused by nitrogen defects.

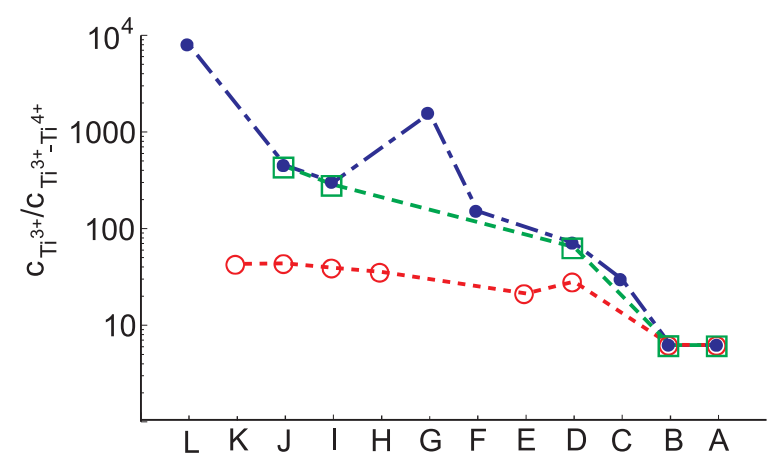

FIG. 14. The ratio of concentrations of $\mathrm{Ti}^{3+}$ to the concentration of $\mathrm{Ti}^{3+}-\mathrm{Ti}^{4+}$ pairs at reference points of $\mathrm{Al}-\mathrm{Ti}-\mathrm{O}-X$ phase diagrams (see Table I) at $T=T_{m}$. Filled circles correspond to $X=\mathrm{C}$, open circles, to $X=\mathrm{N}$, and open squares, to $X=\mathrm{F}$. Lines are guides to the eye. 

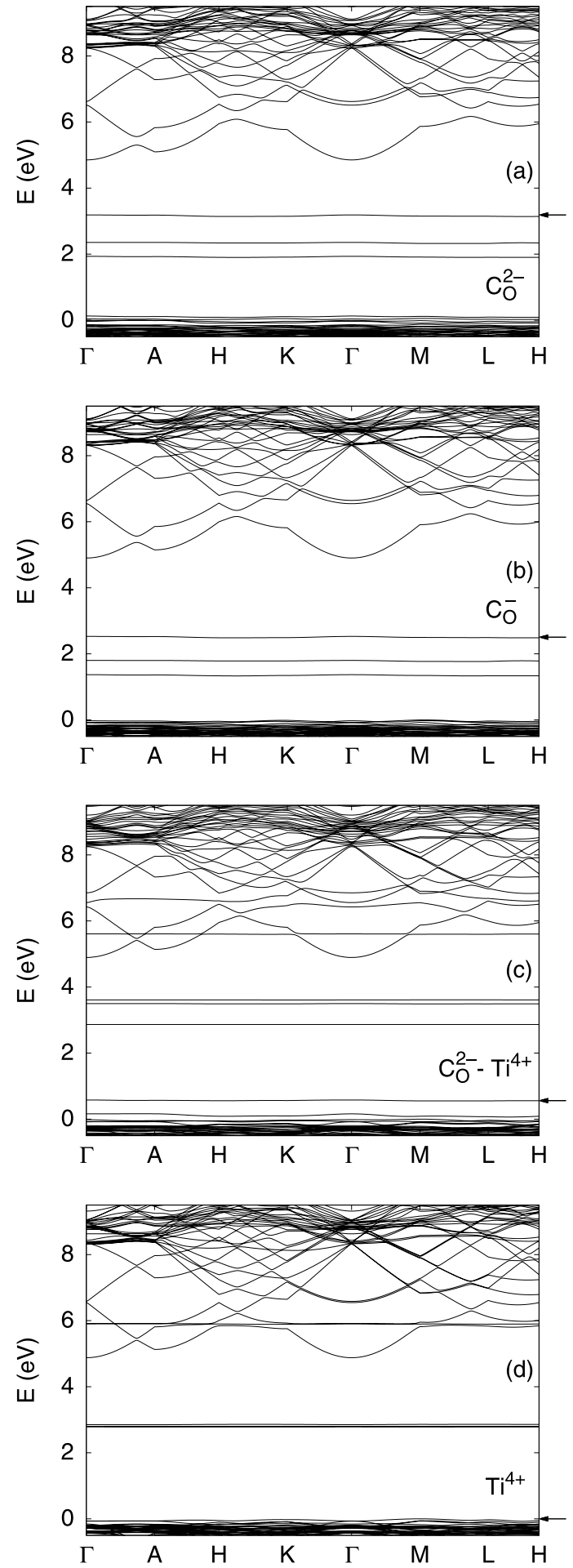

FIG. 15. Band structure of $\mathrm{Al}_{2} \mathrm{O}_{3}$ with $\mathrm{C}_{\mathrm{O}}^{2-}$ (a), $\mathrm{C}_{\mathrm{O}}^{-}$(b), $\mathrm{C}_{\mathrm{O}}^{2-}-\mathrm{Ti}^{4+}$ (c), and $\mathrm{Ti}^{4+}$ (d) defects. The valence band maximum is set at $0 \mathrm{eV}$, and the arrow indicates the position of the highest occupied level.

\section{UNIVERSAL RELATIONS BETWEEN THE CONCENTRATIONS OF $\mathrm{Ti}^{3+}, \mathrm{Ti}^{4+}$, AND $\mathrm{Ti}^{3+}-\mathrm{Ti}^{4+}$}

In this section we discuss whether the observed relations between the concentrations of isolated $\mathrm{Ti}^{3+}$ and $\mathrm{Ti}^{4+}$ defects and $\mathrm{Ti}^{3+}-\mathrm{Ti}^{4+}$ pairs confirm or put in question the pair model of NIR absorption.
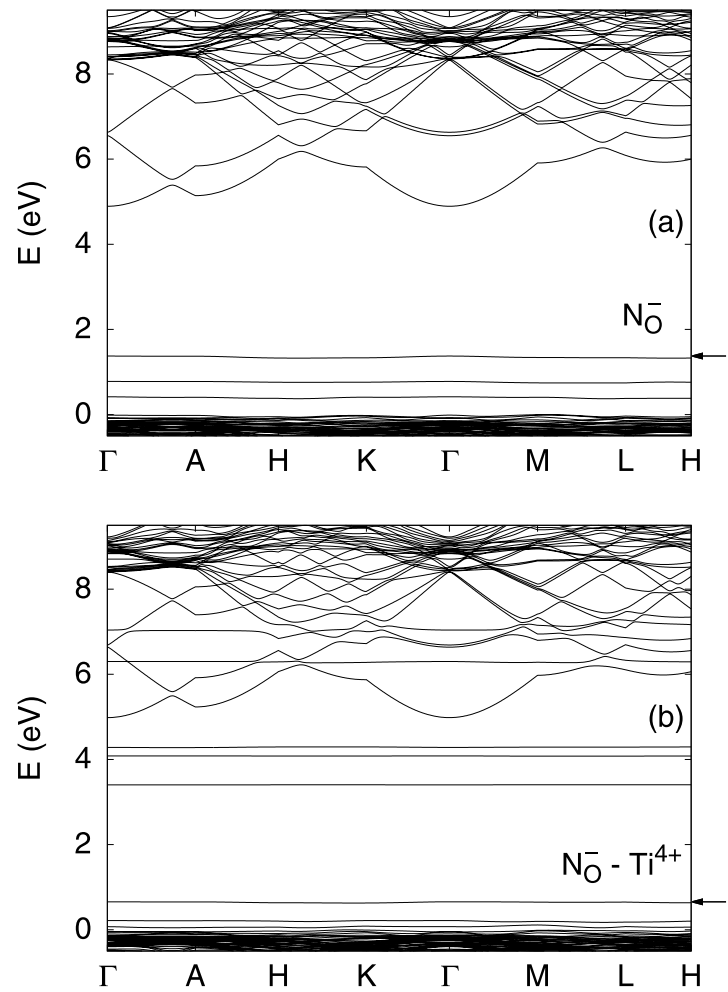

FIG. 16. The same as in Fig. 15 for $\mathrm{N}_{\mathrm{O}}^{-}$(a) and $\mathrm{N}_{\mathrm{O}}^{-}-\mathrm{Ti}^{4+}$ (b).

For samples where the equilibrium concentration of defects was reached at the same temperature, e.g., the samples are annealed at the same $T$, the factor $\exp \left(-E_{3-4}^{(b)} / k_{\mathrm{B}} T\right)$ will be the same and according to Eq. (11) the ratio of the concentration of $\mathrm{Ti}^{3+}$ to the concentration of $\mathrm{Ti}^{3+}-\mathrm{Ti}^{4+}$ will be in inverse proportion to the concentration of $\mathrm{Ti}^{4+}$. Assuming that the $c_{\mathrm{Ti}^{3+}} / c_{\mathrm{Ti}^{3+}{ }_{-\mathrm{Ti}^{4+}}}$ ratio determines the FOM one can expect that the FOM would be in inverse proportion to $c_{\mathrm{Ti}^{4+}}$ as well. At the same time samples annealed at different temperatures will have different coefficients of proportionality between these quantities and their FOM may not demonstrate such a proportionality. Let us consider the following example. We imagine that someone obtained five samples labeled as $\mathrm{c}, \mathrm{d}, \mathrm{f}, \mathrm{i}$, and $\mathrm{j}$. These samples were grown in the conditions that correspond to the reference points $\mathrm{C}, \mathrm{D}, \mathrm{F}, \mathrm{I}$, and $\mathrm{J}$ of the Al-Ti-O-C phase diagram, respectively. According to our calculations (see Fig. 6) these samples should have approximately the same total concentration of $\mathrm{Ti}$, but different concentrations of $\mathrm{Ti}^{4+}$. Then we imagine that each sample was divided into seven parts and 30 samples were annealed in the conditions that correspond to the reference points $\mathrm{C}, \mathrm{G}$, and $\mathrm{L}$ of the Al-O-C phase diagram at two different temperatures, $T=2100 \mathrm{~K}$ and $T=2000 \mathrm{~K}$. The reference points for the Al-O-C diagram and the value of $\mu_{\mathrm{O}}$ at three different temperatures are given in Table $\mathrm{V}$ (under lowering in temperature two reference points, $\mathrm{C}$ and $\mathrm{G}$, disappear and are replaced with the point $\mathrm{C}_{1}$ ). We imply that the total concentration of $\mathrm{Ti}$ is not changed under annealing. As a result there were obtained 35 samples: 5 parent samples $\mathrm{c}, \mathrm{d}, \mathrm{f}, \mathrm{i}$, and $\mathrm{j} ; 15$ samples annealed at $T=2100 \mathrm{~K}$ in the conditions that correspond to the points $\mathrm{C}, \mathrm{G}$, and $\mathrm{L}$ of the Al-O-C phase diagram and labeled as $\mathrm{xCa}$, 

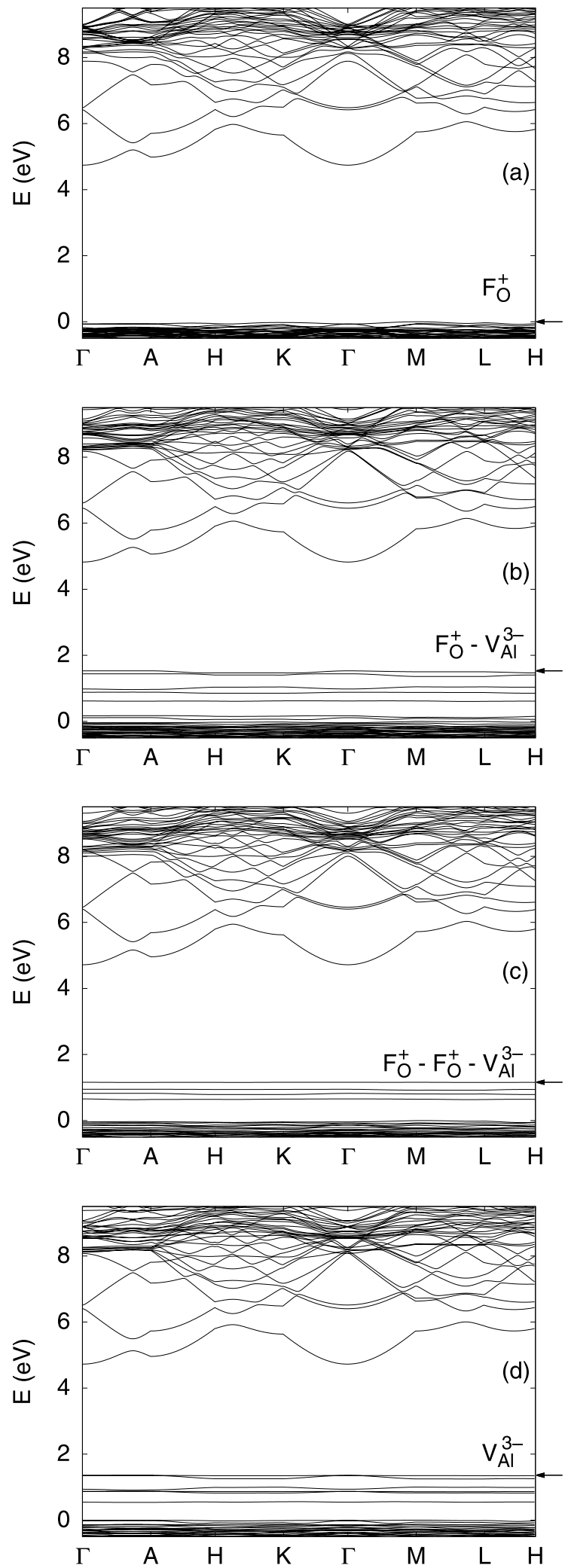

FIG. 17. The same as in Fig. 15 for a $\mathrm{F}_{\mathrm{O}}^{+}$(a), $\mathrm{F}_{\mathrm{O}}^{+}-V_{\mathrm{Al}}^{3-}$ (b), $\mathrm{F}_{\mathrm{O}}^{+}-\mathrm{F}_{\mathrm{O}}^{+}-V_{\mathrm{Al}}^{3-}(\mathrm{c})$, and $V_{\mathrm{Al}}^{3-}(\mathrm{d})$.

$\mathrm{xGa}$, and $\mathrm{xLa}(\mathrm{x}=\mathrm{c}, \mathrm{d}, \mathrm{f}, \mathrm{i}, \mathrm{j})$; and 15 samples annealed at $T=2000 \mathrm{~K}$ and labeled as $\mathrm{xCb}, \mathrm{xGb}$, and $\mathrm{xLb}$, correspondingly. We calculate the $c_{\mathrm{Ti}^{3+}} / c_{\mathrm{Ti}^{3+}-\mathrm{Ti}^{4+}}$ ratio for these samples and plot it against $1 / c_{\mathrm{Ti}^{4+}}$ (Fig. 18). One can see that the
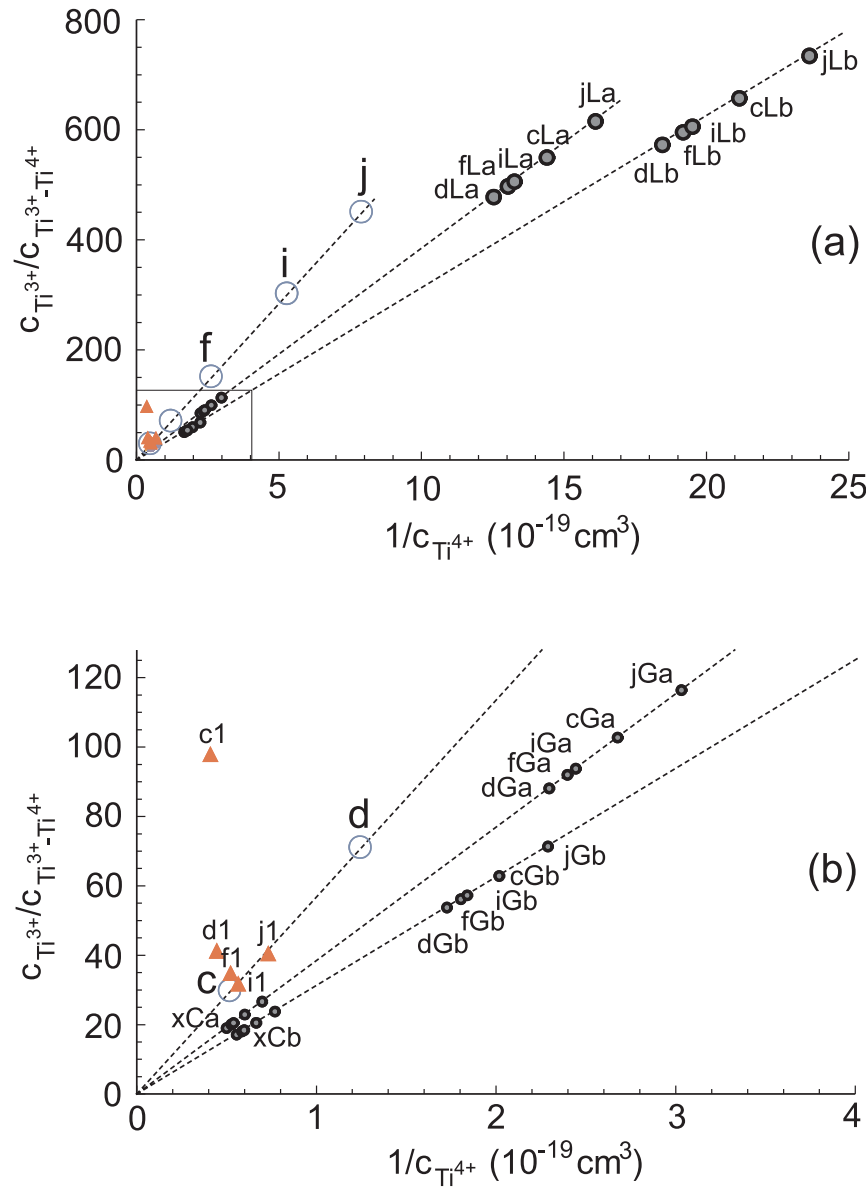

FIG. 18. The $c_{\mathrm{Ti}^{3+}} / c_{\mathrm{Ti}^{3+}-\mathrm{Ti}^{4+}}$ ratio versus the inverse concentration of $\mathrm{Ti}^{4+}$. Open circles show equilibrium concentrations at $T=$ $T_{m}$, filled circles, at $T=2100 \mathrm{~K}$ and $T=2000 \mathrm{~K}$, labeled as xYa and $\mathrm{xYb}$, respectively $(\mathrm{x}=\mathrm{c}, \mathrm{d}, \mathrm{f}, \mathrm{i}, \mathrm{j}$ refers to the parent sample, and $\mathrm{Y}=\mathrm{C}, \mathrm{G}, \mathrm{L}$, to the reference point in the Al-O-C phase diagram). Triangles correspond to equilibrium concentration at $T=1600 \mathrm{~K}$ reached under condition that diffusion of $\mathrm{Ti}$ is suppressed. Dashed lines show linear fit. A rectangle in (a) indicates the area shown in (b) in another scale.

points in Fig. 18 belong to three zero-origin straight lines with different slopes. If one takes randomly several samples from this 35-sample set and measures the FOM one may find that the FOM is not proportional to $1 / c_{\mathrm{Ti}^{4+}}$. But this does not mean that the pair model of NIR absorption is incorrect. This example demonstrates that it is important to investigate samples annealed at the same temperature to verify the pair model of NIR absorption.

The dependencies presented in Fig. 18 also demonstrate that annealing in the reduced conditions (point L) should increase the FOM and the effect is larger at lower temperature of annealing. At the same time annealing in the intermediate conditions (points $\mathrm{G}$ and $\mathrm{C}$ ) may decrease the FOM.

Let us also discuss the possible scenario of violation of proportionality between the FOM and $1 / c_{\mathrm{Ti}^{4+}}$ even for samples annealed at the same temperature. We imply that at rather low temperature the diffusion coefficient for certain defects is so small that such defects can be considered as frozen ones. Let $\mathrm{Ti}$ ions be such defects while $\mathrm{Al}$ vacancies remain mobile 
TABLE V. Oxygen chemical potential at reference points of Al-O-C phase diagram at three different temperatures.

\begin{tabular}{lccccc}
\hline \hline & \multicolumn{4}{c}{ Reference points, phases in equilibrium, $\mu_{\mathrm{O}}(\mathrm{eV})$} \\
\cline { 2 - 5 }$T(\mathrm{~K})$ & $\mathrm{A}$ & $\mathrm{C}$ & $\mathrm{C}_{1}$ & $\mathrm{G}$ & $\mathrm{L}$ \\
\hline 2100 & $\mathrm{Al}_{2} \mathrm{O}_{3}, \mathrm{O}_{2}, \mathrm{CO}_{2}$ & $\mathrm{Al}_{2} \mathrm{O}_{3}, \mathrm{CO}_{2}, \mathrm{CO}$ & $\mathrm{Al}_{2} \mathrm{O}_{3}, \mathrm{CO}_{2}, \mathrm{C}$ & $\mathrm{Al}_{2} \mathrm{O}_{3}, \mathrm{CO}, \mathrm{C}$ & $\mathrm{Al}_{2} \mathrm{O}_{3}, \mathrm{C}, \mathrm{Al}$ \\
2000 & -6.97 & -9.11 & & -9.73 & -10.38 \\
1600 & -6.83 & -9.06 & -9.50 & -10.35 \\
\hline \hline
\end{tabular}

ones. To calculate concentrations of Ti defects we take into account two additional constraints:

$$
\begin{gathered}
c_{\mathrm{Ti}^{3+}}+c_{\mathrm{Ti}^{4+}}+c_{\mathrm{Ti}^{4+}-V_{\mathrm{Al}}^{3-}}=c_{1}=\text { const. } \\
c_{\mathrm{Ti}^{3+}-\mathrm{Ti}^{3+}}+c_{\mathrm{Ti}^{3+}-\mathrm{Ti}^{4+}}+c_{\mathrm{Ti}^{4+}-\mathrm{Ti}^{4+}-V_{\mathrm{Al}}^{3-}} \\
+c_{\mathrm{Ti}^{3+}-\mathrm{Ti}^{4+}-V_{\mathrm{Al}}^{3-}}+c_{\mathrm{Ti}^{3+}-\mathrm{Ti}^{3+}-V_{\mathrm{Al}}^{3-}}=c_{2}=\text { const. }
\end{gathered}
$$

These constraints forbid formation of new Ti clusters and dissociation of existing Ti clusters. The concentrations of defects with one $\mathrm{Ti}\left(c_{1}\right)$ and with two $\mathrm{Ti}$ ions $\left(c_{2}\right)$ calculated for the same imaginary samples $c, d, f, i$, and $j$ are shown in Fig. 19. For the system with the constraints (36) and (37). the relation (9) is not satisfied. Therefore the relation (11) is violated, which can be demonstrated by direct calculations.

We calculate equilibrium concentration of $\mathrm{Ti}^{3+}, \mathrm{Ti}^{4+}$, and $\mathrm{Ti}^{3+}-\mathrm{Ti}^{4+}$ under the constraints (36) and (37) at $T=1600 \mathrm{~K}$ (we imply that the frozen regime is reached at this temperature). We fix $\mu_{\mathrm{O}}$ that corresponds to the point $\mathrm{C}_{1}$ (Table $\mathrm{V}$ ). The quantities $c_{1}$ and $c_{2}$ are fixed to ones as in the samples $\mathrm{c}, \mathrm{d}, \mathrm{f}, \mathrm{i}$, and $\mathrm{j}$. The results of the calculations are shown in Fig. 18 by triangles labeled as $\mathrm{c} 1, \mathrm{~d} 1, \mathrm{f} 1, \mathrm{i} 1$, and $\mathrm{j} 1$. One can see that indeed $c_{\mathrm{Ti}^{3+}} / c_{\mathrm{Ti}^{3+} \mathrm{Ti}^{4+}}$ is not proportional to $1 / c_{\mathrm{Ti}^{4+}}$. Comparing Figs. 18 and 19 we find that $c_{\mathrm{Ti}^{3+}} / c_{\mathrm{Ti}^{3+}-\mathrm{Ti}^{4+}}$

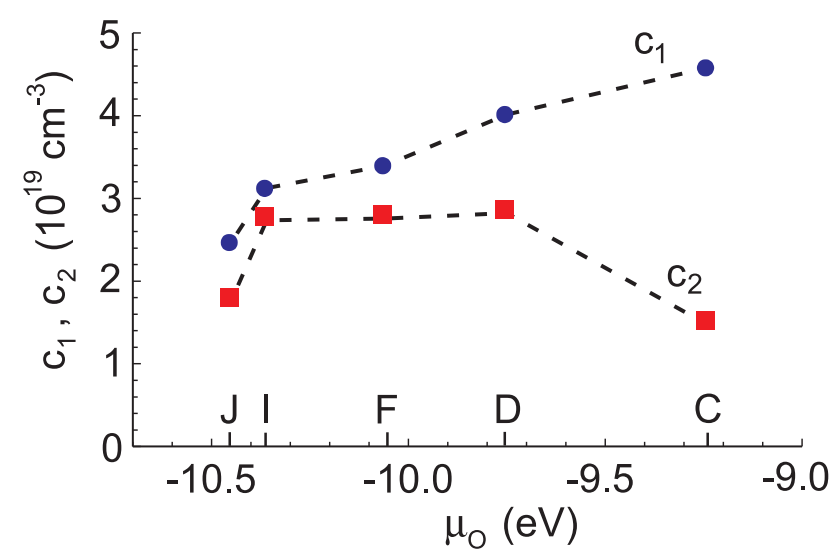

FIG. 19. Sum of equilibrium concentrations of isolated $\mathrm{Ti}$ and pairs $\mathrm{Ti}^{4+}-V_{\mathrm{Al}}\left(c_{1}\right)$ and sum of concentrations of Ti-Ti pairs and Ti-Ti- $V_{\mathrm{Al}}$ triples $\left(c_{2}\right)$ at $T=T_{m}$ in the conditions that correspond to the point $\mathrm{C}, \mathrm{D}, \mathrm{F}, \mathrm{I}, \mathrm{J}$ of the Al-Ti-O-C phase diagram (Fig. 5). correlates with the $c_{1} / c_{2}$ ratio. Note that the violation of the relation (11) and more general relation (9) is caused solely by the additional constraints (36) and (37), and therefore this effect most probably holds true for a wide range of "freezing" temperatures.

To conclude this analysis we discuss one more feature observed in Ref. [13]. It was found in Ref. [13] that for some sets of samples the absorption coefficient $\alpha_{820}$ is proportional to the square of the absorption coefficient $\alpha_{490}$. If NIR absorption is caused by $\mathrm{Ti}^{3+}-\mathrm{Ti}^{4+}$ pairs such a behavior means that the concentration of $\mathrm{Ti}^{3+}-\mathrm{Ti}^{4+}$ pairs is proportional to the square of the concentration of $\mathrm{Ti}^{3+}$ isolated ions. It cannot be the general property. Nevertheless our calculations show that for the samples annealed at the same $\mu_{\mathrm{O}}$ this property is satisfied at least approximately. We specify $\mu_{\mathrm{O}}=-10.0 \mathrm{eV}$ and calculate equilibrium concentrations of defects at $T=$ $T_{m}, T=2100 \mathrm{~K}$, and $T=2000 \mathrm{~K}$ assuming that the total concentration of $\mathrm{Ti} c_{\mathrm{Ti}}$ is fixed. We consider 20 different $c_{\mathrm{Ti}}$ in the range from $5 \times 10^{18} \mathrm{~cm}^{-3}$ to $10^{20} \mathrm{~cm}^{-3}$. Obtained concentrations of $\mathrm{Ti}^{3+}-\mathrm{Ti}^{4+}$ are plotted in Fig. 20 against the concentration of $\mathrm{Ti}^{3+}$. One can see that for given $T$ the law $c_{\mathrm{Ti}^{3+} \mathrm{Ti}^{4+}}=\kappa c_{\mathrm{Ti}^{3+}}^{2}$ is satisfied. The coefficient $\kappa$ weakly depends on temperature. Thus the observed in Ref. [13] correspondence between $\alpha_{820}$ and $\alpha_{490}$ does not contradict the pair model of NIR absorption.

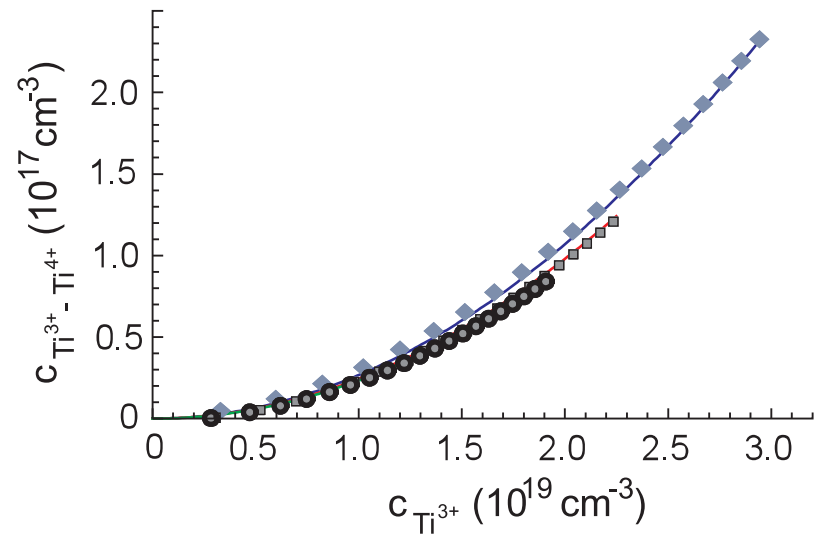

FIG. 20. Dependence of the concentration of $\mathrm{Ti}^{3+}-\mathrm{Ti}^{4+}$ on the concentration of $\mathrm{Ti}^{3+}$ calculated for the case where equilibrium concentrations are reached at fixed total $\mathrm{Ti}$ concentration at $\mu_{\mathrm{O}}=$ $-10.0 \mathrm{eV}$ and $T=T_{m}$ (diamonds), $T=2100 \mathrm{~K}$ (squares), and $T=$ $2000 \mathrm{~K}$ (circles). Lines show the quadratic fit. Total concentration of Ti is varied from $5 \times 10^{18} \mathrm{~cm}^{-3}$ to $10^{20} \mathrm{~cm}^{-3}$. 


\section{CONCLUSION}

In conclusion, with reference to Ti:doped sapphire we analyzed factors that determine the charge state of dopants in insulating crystals. Basing on DFT calculation combined with thermochemical data we found that $\mathrm{Ti}$ atoms enter into the $\mathrm{Al}_{2} \mathrm{O}_{3}$ crystal predominantly in the form of substitutional $\mathrm{Ti}^{3+}$ and $\mathrm{Ti}^{4+}$ ions. An essential fraction of such defects bind in pairs, triples, etc., or form complexes with Al vacancies.

For laser applications it is important to reduce the concentration of $\mathrm{Ti}^{3+}-\mathrm{Ti}^{4+}$ pairs keeping concentration of unpaired $\mathrm{Ti}^{3+}$ ions at a high level. To increase the $c_{\mathrm{Ti}^{3+}} / c_{\mathrm{Ti}^{3+}-\mathrm{Ti}^{4+}}$ ratio to the level of $10^{3}$ or higher the crystals should be grown or annealed in the reduced conditions. Alternatively one can fix the total concentration of $\mathrm{Ti}$ at a relatively low level $\left(\lesssim 10^{18} \mathrm{~cm}^{-3}\right)$. Annealing in conditions that correspond to intermediate values of the oxygen chemical potential may result in a decrease of the $c_{\mathrm{Ti}^{3+}} / c_{\mathrm{Ti}^{3+}-\mathrm{Ti}^{4+}}$ ratio.

We have shown that codopants that form charged defects may change relative concentrations of the main dopants in different charge states. In particular, we have found that growth or annealing of Ti:sapphire in the presence of nitrogen compounds results in the appearance of a large number of negatively charged nitrogen defects that cause a decrease of the $c_{\mathrm{Ti}^{3+}} / c_{\mathrm{Ti}^{3+}-\mathrm{Ti}^{4+}}$ ratio.

We have demonstrated that growth or annealing of doped crystals in the presence of additional compounds may influence the charge state of dopants indirectly. Such a situation is realized in Ti:sapphire grown or annealed in the presence of carbon or its compounds. Carbon defects have large formation energies and their equilibrium concentrations are quite low. Nevertheless the presence of carbon and its compounds may increase the $c_{\mathrm{Ti}^{3+}} / c_{\mathrm{Ti}^{3+}-\mathrm{Ti}^{4+}}$ ratio due to lowering of the oxygen chemical potential and increasing of the titanium chemical potential.

We analyze the general relation between the concentrations of isolated and complex defects. We find that normally the concentration of complex defects is proportional to the product of concentrations of isolated defects which form the complex defect. The coefficient of proportionality depends on the binding energy and on the temperature of annealing or the melting temperature (for as-grown samples). This relation is violated if some defects are frozen. Such a situation is expected at rather low temperature of annealing. In application to Ti:sapphire it means that the $c_{\mathrm{Ti}^{3+}} / c_{\mathrm{Ti}^{3+}-\mathrm{Ti}^{4+}}$ ratio and FOM are proportional for the inverse concentration of $\mathrm{Ti}^{4+}$ only for samples annealed at the same temperature and even in that case such a proportionality can be violated if the temperature of annealing is quite low.

\section{ACKNOWLEDGMENT}

This work was performed using computational facilities of the joint computational cluster of the State Scientific Institution "Institute for Single Crystals" and the Institute for Scintillation Materials of the National Academy of Sciences of Ukraine incorporated into the Ukrainian National Grid.
[1] L. Y. Kravchenko and D. V. Fil, Defect complexes in Ti-doped sapphire: A first-principles study, J. Appl. Phys. 123, 023104 (2018).

[2] P. F. Moulton, Ti-doped sapphire: Tunable solid-state laser, Opt. News 8, 9 (1982).

[3] P. F. Moulton, Spectroscopic and laser characteristics of Ti: $\mathrm{Al}_{2} \mathrm{O}_{3}$, J. Opt. Soc. Am. B 3, 125 (1986).

[4] P. Lacovara, L. Esterowitz, and M. Kokta, Growth, spectroscopy, and lasing of titanium-doped sapphire, IEEE J. Quantum Electron. 21, 1614 (1985).

[5] W. C. Wong, D. S. McClure, S. A. Basun, and M. R. Kokta, Charge-exchange processes in titanium-doped sapphire crystals. I. Charge-exchange energies and titanium-bound excitons, Phys. Rev. B 51, 5682 (1995).

[6] S. V. Nizhankovskii, N. S. Sidel'nikova, and V. V. Baranov, Optical absorption and color centers in large Ti:Sapphire crystals grown by horizontally directed crystallization under reducing conditions, Phys. Solid State 57, 781 (2015).

[7] A. J. Strauss, R. E. Fahey, A. Sanchez, and R. L. Aggarwal, Growth and characterization of Ti: $\mathrm{A}_{2} \mathrm{O}_{3}$ crystals for laser applications, Proc. SPIE 681, 62 (1987).

[8] A. Sanchez, A. J. Strauss, R. L. Aggarwal, M. M. Stuppi, R. E. Fahey, W. R. Rapoport, and C. P. Khattak, Crystal growth, spectroscopy, and laser characteristics of $\mathrm{Ti}: \mathrm{Al}_{2} \mathrm{O}_{3}$, IEEE J. Quantum Electron. 24, 995 (1988).

[9] R. L. Aggarwal, A. Sanchez, M. M. Stuppi, R. E. Fahey, A. J. Strauss, W. R. Rapoport, and C. P. Khattak, Residual infrared absorption in as-grown and annealed crystals of Ti: $\mathrm{Al}_{2} \mathrm{O}_{3}$, IEEE J. Quantum Electron. 24, 1003 (1988).
[10] W. R. Rapoport and C. P. Khattak, Titanium sapphire laser characteristics, Appl. Opt. 27, 2677 (1988).

[11] J. F. Pinto, L. Esterowitz, G. H. Rosenblatt, M. Kokta, and D. Peressini, Improved Ti:Sapphire laser performance with new high figure of merit crystals, IEEE J. Quantum Electron. 30, 2612 (1994).

[12] F. X. Zha, J. H. Zhang, and S. D. Xia, Electronic structure of the ion pair model for Ti: $\mathrm{Al}_{2} \mathrm{O}_{3}$, J. Phys.: Condens. Matter 6, 6497 (1994).

[13] P. F. Moulton, J. G. Cederberg, K. T. Stevens, G. Foundos, M. Koselja, and J. Preclikova, Characterization of absorption bands in Ti:sapphire crystals, Opt. Mater. Express 9, 2216 (2019).

[14] K. Matsunaga, A. Nakamura, T. Yamamoto, and Y. Ikuhara, First-principles study of defect energetics in titanium-doped alumina, Phys. Rev. B 68, 214102 (2003).

[15] K. Matsunaga, T. Mizoguchi, A. Nakamura, T. Yamamoto, and Y. Ikuhara, Formation of titanium-solute clusters in alumina: A first-principles study, Appl. Phys. Lett. 84, 4795 (2004).

[16] S. B. Zhang and J. E. Northrup, Chemical Potential Dependence of Defect Formation Energies in GaAs: Application to Ga SelfDiffusion, Phys. Rev. Lett. 67, 2339 (1991).

[17] C. Freysoldt, B. Grabowski, T. Hickel, J. Neugebauer, G. Kresse, A. Janotti, and C. G. Van de Walle, First-principles calculations for point defects in solids, Rev. Mod. Phys. 86, 253 (2014).

[18] J. M. Soler, E. Artacho, J. D. Gale, A. Garcia, J. Junquera, P. Ordejon, and D. Sanchez-Portal, The SIESTA method for 
$a b$ initio order- $N$ materials simulation, J. Phys.: Condens. Matter 14, 2745 (2002).

[19] B. E. Tegner and G. J. Ackland, Pseudopotential errors in titanium, Comput. Mater. Sci. 52, 2 (2012).

[20] K. Reuter and M. Scheffler, Composition, structure, and stability of $\mathrm{RuO}_{2}(110)$ as a function of oxygen pressure, Phys. Rev. B 65, 035406 (2001).

[21] K. Reuter and M. Scheffler, First-Principles Atomistic Thermodynamics for Oxidation Catalysis: Surface Phase Diagrams and Catalytically Interesting Regions, Phys. Rev. Lett. 90, 046103 (2003).

[22] M. W. Chase, Jr., NIST-JANAF Thermochemical Tables, 4th ed. (American Chemical Society and American Institute of Physics, New York, 1998).

[23] N. D. M. Hine, K. Frensch, W. M. C. Foulkes, and M. W. Finnis, Supercell size scaling of density functional theory formation energies of charged defects, Phys. Rev. B 79, 024112 (2009).

[24] N. D. M. Hine, P. D. Haynes, A. A. Mostofi, and M. C. Payne, Linear-scaling density-functional simulations of charged point defects in $\mathrm{Al}_{2} \mathrm{O}_{3}$ using hierarchical sparse matrix algebra, J. Chem. Phys. 133, 114111 (2010).

[25] G. Makov and M. C. Payne, Periodic boundary conditions in $a b$ initio calculations, Phys. Rev. B 51, 4014 (1995).
[26] H.-P. Komsa, T. T. Rantala, and A. Pasquarello, Finite-size supercell correction schemes for charged defect calculations, Phys. Rev. B 86, 045112 (2012).

[27] M. Choi, J. L. Lyons, A. Janotti, and C. G. Van de Walle, Impact of carbon and nitrogen impurities in high- $\kappa$ dielectrics on metal-oxide-semiconductor devices, Appl. Phys. Lett. 102, 142902 (2013).

[28] J. Zhu, K. P. Muth, and R. Pandey, Stability and electronic properties of carbon in $\alpha-\mathrm{Al}_{2} \mathrm{O}_{3}, \mathrm{~J}$. Phys. Chem. Solids 75, 379 (2014).

[29] L. Ao, Y. G. Yuan, Y. Tian, J. L. Nie, H. Y. Xiao, H. Chen, X. Xiang, and X. T. Zu, Electronic and magnetic properties of Cdoped $\alpha-\mathrm{Al}_{2} \mathrm{O}_{3}$ by DFT calculations, Comput. Mater. Sci. 110, 368 (2015).

[30] S. V. Nizhankovskiy, N. S. Sidelnikova, and V. V. Baranov, Influence of crystal growth conditions and carbothermal treatment on activator charge state in Ti:sapphire, Funct. Mater. 25, 208 (2018).

[31] J. Zhang, J. Ding, and Y. Zhang, Electronic and optical properties of $\mathrm{Ti}^{3+}$ doped $\alpha-\mathrm{Al}_{2} \mathrm{O}_{3}$ crystals: First-principles calculations, Solid State Commun. 149, 1188 (2009).

[32] M. G. Brik, $A b$ initio studies of the electronic and optical properties of $\mathrm{Al}_{2} \mathrm{O}_{3}: \mathrm{Ti}^{3+}$ laser crystals, Phys. B (Amsterdam) 532, 178 (2018). 